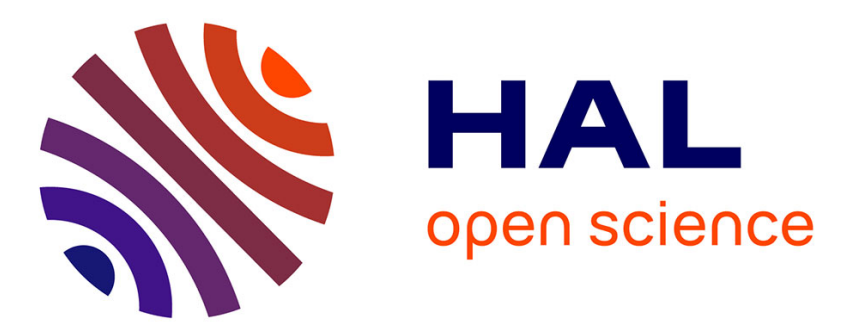

\title{
Genomic signatures of clonality in the deep water kelp Laminaria rodriguezii Genomic signatures of clonality
}

Lauric Reynes, Thierry Thibaut, Stéphane Mauger, Aurelie Blanfuné, Florian Holon, Corinne Cruaud, Arnaud Couloux, Myriam Valero, Didier Aurelle

\section{- To cite this version:}

Lauric Reynes, Thierry Thibaut, Stéphane Mauger, Aurelie Blanfuné, Florian Holon, et al.. Genomic signatures of clonality in the deep water kelp Laminaria rodriguezii Genomic signatures of clonality. Molecular Ecology, 2021, 10.1111/mec.15860 . hal-03159657

\section{HAL Id: hal-03159657 https://hal.science/hal-03159657}

Submitted on 4 Mar 2021

HAL is a multi-disciplinary open access archive for the deposit and dissemination of scientific research documents, whether they are published or not. The documents may come from teaching and research institutions in France or abroad, or from public or private research centers.
L'archive ouverte pluridisciplinaire HAL, est destinée au dépôt et à la diffusion de documents scientifiques de niveau recherche, publiés ou non, émanant des établissements d'enseignement et de recherche français ou étrangers, des laboratoires publics ou privés. 


\section{Genomic signatures of clonality in the deep water kelp Laminaria}

2

3

\section{5}

4 Lauric Reynes ${ }^{1}$, Thierry Thibaut ${ }^{1}$, Stéphane Mauger ${ }^{2}$, Aurélie Blanfuné ${ }^{1}$, Florian

5 Holon $^{3}$, Corinne Cruaud ${ }^{4}$, Arnaud Couloux ${ }^{5}$, Myriam Valero ${ }^{2}$, Didier Aurelle ${ }^{1,6}$

*lauric.reynes@mio.osupytheas.fr

(1) Aix Marseille Univ, Université de Toulon, CNRS, IRD, MIO, Marseille, France

(2) IRL 3614, Evolutionary Biology and Ecology of Algae, CNRS, Sorbonne Université, UC, UACH, CS 90074 , Place Georges Teissier, 29688 Roscoff, France

(3) Andromède Océanologie, Montpellier, France

(4) Genoscope, Institut de Biologie François-Jacob, Commissariat à l'Energie Atomique (CEA), Université Paris-Saclay, F-91057 Evry, France.

(5) Génomique Métabolique, Genoscope, Institut François Jacob, CEA, CNRS, Univ Evry, Université Paris-Saclay, 91057 Evry, France

(6) Institut de Systématique Évolution Biodiversité (ISYEB, UMR 7205), Muséum National d'Histoire Naturelle, CNRS, Sorbonne Université, EPHE, 57 rue Cuvier, CP 51, 75005 Paris, France 
Partial clonality, mode of reproduction, heterozygote excess, population genomics, kelp

The development of population genomic approaches in non-model species allows for renewed studies of the impact of reproductive systems and genetic drift on population diversity. Here, we investigate the genomic signatures of partial clonality in the deep water kelp Laminaria rodriguezii, known to reproduce by both sexual and asexual means. We compared these results with the species Laminaria digitata, a closely related species that differs by different traits, in particular its reproductive mode (no clonal reproduction). We analysed genome-wide variation with dd-RAD sequencing using 4077 SNPs in L. rodriguezii and 7364 SNPs in $L$. digitata. As predicted for partially clonal populations, we show that the distribution of $F_{I S}$ within populations of $L$. rodriguezii is shifted toward negative values, with a high number of loci showing heterozygote excess. This finding is the opposite of what we observed within sexual populations of $L$. digitata, characterized by a generalized deficit in heterozygotes. Furthermore, we observed distinct distributions of $F_{I S}$ among populations of $L$. rodriguezii, which is congruent with the predictions of theoretical models for different levels of clonality and genetic drift. These findings highlight that the empirical distribution of $F_{I S}$ is a promising feature for the genomic study of asexuality in natural populations. Our results also show that the populations of $L$. rodriguezii analysed here are genetically differentiated and probably isolated. Our study provides a conceptual framework to investigate partial clonality on the basis of RAD-sequencing SNPs. These results could be obtained without any reference genome, and are therefore of interest for various non-model species. 


\section{INTRODUCTION}

Partial clonality, defined as a mode of reproduction where species reproduce both sexually and asexually, occurs in a wide variety of organisms across the tree of life, and is particularly widespread in fungi, plants, rotifers, cladocerans and insects (Halkett et al., 2005). Clonal reproduction can occur through different mechanisms such as fragmentation, vegetative reproduction, mitotic parthenogenesis, or some forms of meiotic parthenogenesis (De Meeûs et al., 2007; Jaron et al., 2020). Partial clonality has attracted considerable attention among evolutionary biologists due to the potential effects of asexuality on the evolutionary trajectory of species since reproductive modes have a major impact on the level of genome-wide genetic diversity and its distribution within and among populations (Halkett et al., 2005; Duminil et al., 2007). Moreover, reproductive modes profoundly affect other biological traits that play important roles in colonization processes and the spread of populations, such as population growth and dispersal (Kettenring \& Mock, 2012; González de León et al., 2016), and in buffering and resilience after catastrophic events (Becheler et al., 2020).

Theoretical models predict that when clonality predominates, it will increase heterozygosity (Marshall \& Weir, 1979; Balloux et al., 2003; De Meeûs et al., 2006), which may ultimately lead to higher levels of observed heterozygosity $\left(H_{0}\right)$ than those expected $\left(H_{e}\right)$ under panmixia. This deviation has been observed empirically through negative values of fixation index $F_{I S}$, reported in various partially clonal populations (in animals Adjeroud et al., 2014; Halkett et al., 2005; angiosperms Alberto et al., 2002; Alberto et al., 2005; Arnaud-Haond et al., 2007, and red and brown macroalgae Guillemin et al., 2008; Ardehed et al., 2015; Coleman \& Wernberg, 2018, Pardo et al., 2019). Without sex, alleles do not segregate independently, which implies that heterozygosity can be preserved rather than reduced over generations (Judson \& Normark, 1996). Increasing clonal reproduction can increase effective population size at the allelic scale but it decreases the genotypic effective population size: as a consequence asexual populations can maintain higher allele diversity but lower genotype diversity compared to sexual ones (Balloux et al., 2003). Asexual reproduction also leads to specific patterns of the distribution of $F_{\text {IS }}$ over the genome, characterized by a high occurrence of extreme, mainly negative, values (Stoeckel \& Masson, 2014; Reichel et al., 2016). These last theoretical studies reported, among other points, that high rates of asexuality increased the variance of the distribution of $F_{I S}$ compared to that obtained from fully sexual populations (Stoeckel \& Masson, 2014) but also 
as compared to fully clonal populations (De Meeûs et al. 2006). Some variation in Fis among loci can also indicate the occurrence of rare recombination events as in the automictic parthenogenetic species Artemia parthenogenetica (Nougué et al., 2015). In addition, if asexuality is stable over generations, the accumulation of mutations in different alleles can increase sequence differences among alleles, which corresponds to the "Meselson effect" (Birky 1996; Judson \& Normark, 1996; Balloux et al., 2003; De Meeûs et al., 2007). This effect has been empirically demonstrated in ancient asexual Timema stick-insects (Schwander et al., 2011) and in the human pathogen Trypanosoma brucei gambiense (Koffi et al., 2009; Weir et al., 2016) and Candida albicans (Nébavi et al., 2006). Conversely the long term persistence without sex of Bdelloid rotifers, referred as asexual scandals, has been challenged by the suggestion of non-canonical sex (Schwander, 2016).

In this paper, we investigated how population genomic studies of partially clonal species allow analysis of both the rate of clonality and its consequences for the distribution of $F_{1 S}$. With the development of thousands of Single Nucleotide Polymorphism (SNP), we will test whether the observed empirical distribution of $F_{I S}$ follows the aforementioned predicted variations in $F_{\text {IS }}$ among loci. The development of reduced representation sequencing methods (see for review Davey et al., 2011) now allows such investigations in non-model species. These approaches are also useful to more precisely delineate clonal lineages, where microsatellite loci have failed to detect any genetic variation, as in the case of the selfing species Sargassum muticum in the introduction range (Le Cam et al., 2019). Among the diversity of reduced representation sequencing methods, Restriction Site Associated DNA sequencing (RAD sequencing; Baird et al., 2008) is useful to efficiently develop enough SNPs to study the genomic distribution of population genetic statistics.

We used the kelp Laminaria rodriguezii as a model species for the study of partial clonality. Laminaria rodriguezii is a deep water kelp endemic to the Mediterranean Sea, mainly reported from depths below $70 \mathrm{~m}$, rarely found in shallower waters on seamounts or in upwelling systems (Ballesteros, 2006), and with a maximum depth recorded at $260 \mathrm{~m}$ in the Adriatic Sea (Ercegović, 1960). The rare populations of this species are exposed to various levels of disturbances, such as direct destruction by fishing gear and a decline in water transparency, which has led to L. rodriguezii being classified as endangered (Zuljevic et al., 2016). Besides sexual reproduction, $L$. rodriguezii can reproduce asexually by stoloniferous or rhizoidal growth. This mode of asexual reproduction involves somatic cells and should lead to clonal 
lineages. Vegetative reproduction is only known in two Laminaria species: L. rodriguezii (Huvé, 1955) and the northeast Pacific L. sinclairii (Demes \& Graham, 2011). Laminaria rodriguezii can also reproduce sexually with a haplo-diplobiontic life cycle involving the alternation of microscopic dioicous unisexual haploid gametophytes with large diploid sporophytes typically found in kelps (Bringloe et al., 2020). Even if we do not know the importance of self incompatibility in this species, self fertilisation (i.e. fertilisation between male and female gametophytes originating from a single sporophyte parent), was reported to be possible experimentally in most studied species of Laminariales (see the recent review of Goecke et al., 2020). Laminaria rodriguezii then presents a mixed reproductive system, for which the genetic consequences have not been studied. This deep water species is also characterized by small and highly fragmented populations (Araújo et al., 2016). Therefore, the populations of L. rodriguezii should be impacted by a reduction in genetic polymorphism through drift, a reduction that can be counterbalanced by the aforementioned effects of asexual reproduction on allele diversity (Balloux et al., 2003).

We specifically studied here whether the levels of asexual reproduction have discernable effects on the empirical genomic distribution of diversity and $F_{I S}$ among loci. We included populations of the fully sexual congeneric species, L. digitata, with different levels of microsatellite genetic diversity (Liesner et al., 2020) to take into account the consequence of the mode reproduction with the confounding effect of variation in the strength of genetic drift in our interpretations. Laminaria digitata is analysed only for comparative purposes, and we did not develop the study of the genetic structure of this species in this article. We also interpret our results in the light of previous theoretical studies, especially considering the full distribution of $F_{I S}$ among loci (Stoeckel \& Masson, 2014). Among other factors, we tested whether the clonal rates in populations of $L$. rodriguezii lead to a shift toward highly negative FIS values among loci, as expected for the highest levels of clonality (Stoeckel \& Masson, 2014). We used a large set of SNPs in order to access the most complete distribution of $F_{\text {IS }}$ values over populations of genomes. We also evaluated the robustness of our results by considering different cutoffs in the filtering of SNPs. The implications of the inferred genetic diversity and genetic structure for the management and conservation of this rare deep water kelp $L$. rodriguezii are discussed. 


\section{Sampling, DNA extraction}

147

Individuals of $L$. rodriguezii were sampled from four sites in the Mediterranean, three in Eastern Provence (Banc Magaud_1, Banc Magaud_2, Cap Camarat) and one in Southern Corsica (Bonifacio), between 65 to 76 meters depth (Figure 1). Sampling was done by scuba divers between June and August 2018. Sampling for DNA collection was performed by collecting a small piece of tissue from the blade of sporophytes. More precisely, a total of 47 samples were collected from sporophytes not connected to each other by a stolon, and with a minimum distance of two meters between sampled blades. This strategy aimed to promote the sampling of distinct genets. For one of the two Banc du Magaud sites, namely Banc Magaud_2, we used a different sampling design: the spatial distance between the sampled sporophytes was recorded along a regular transect of 20 meters to study the spatial genetic structure inside the population. Regarding L. digitata, we used samples from five northeastern Atlantic populations of L. digitata collected in 2018 (Table S1, Supporting Information). Genomic DNA was extracted using the Nucleospin ${ }^{\circledR} 96$ plant kit (Macherey-Nagel, Düren, Germany), according to the manufacturer's protocol.

\section{ddRAD-sequencing}

Two double-digest RAD-sequencing libraries (ddRAD-seq) with 47 individuals of $L$. rodriguezii and 125 individuals of L. digitata were prepared according to Peterson et al., (2012). To minimize bias in library preparation, all DNA samples were randomized across libraries, and two and five replicates of $L$. rodriguezii and L. digitata, respectively, were included. DNA concentrations were estimated with PicoGreen (Invitrogen, Carlsbad, CA, USA), and 100 ng of genomic DNA was double digested using Pstl and Hhal (NEB) for 12 hours at $37^{\circ} \mathrm{C}$. The purification of digested DNA was conducted by the NucleoMag NGS clean-up and size select kit (Macherey-Nagel, Düren, Germany) according to the manufacturer's protocol. When these steps were completed, the ligation of sequencing adapters to restriction digested DNA was performed as follows: P1 adapters (overhang Pstl), including unique barcodes (6-12 bp) and P2 universal adaptor (overhang Hhal) were ligated to DNA using $0.5 \mu \mathrm{l}(400 \mathrm{U} / \mu \mathrm{L})$ of T4 DNA ligase (NEB), $6 \mu$ l of 10X T4 ligase buffer (NEB) and incubated for 12 hours at room 
temperature. Before PCR amplification, an additional purification step was done with the NucleoMag NGS clean-up and size select kit. Amplification by PCR was restricted to 15 cycles and performed with the Q5 hot Start High-Fidelity DNA polymerase kit (NEB). Then, samples were multiplexed, and automated size selected for a range between 400 and $900 \mathrm{bp}$ using a Pippin Prep (Sage Science, Beverly, MA, USA). Finally, the libraries were sequenced with the paired-end method (2×150 bp) on an Illumina Hiseq 4000 platform (Génome Québec Innovation Centre, McGill Univ., Montreal, Canada).

\section{Genotyping and SNP filtering}

Raw quality reads were checked using FastQC v0.11.7 (Andrews, 2010) and trimmed to 137 bp after the removal of adapters sequencing by Trimmomatic (Bolger et al., 2014). Then, paired-reads were demultiplexed by both index and barcode using Stacks's process_radtags (Catchen et al., 2011). Thanks to the phylogenetic proximity between $L$. rodriguezii and $L$. digitata (Žuljević et al., 2016), we were able to use the draft genome of L. digitata (unpublished data, Mark Cock) to align our reads with the BWA-mem algorithm in BWA v0.7.17 (Li \& Durbin, 2009). Aligned reads were then assembled into loci and finally, we called single nucleotide polymorphisms (SNPs) with the Stacks v2.4 pipeline (Rochette et al., 2019). Aligned reads of mapping quality below 30 (which means a probability of incorrect alignment below 0.001 ) were excluded to minimize errors resulting from the erroneous assembly of paralogous loci as a single locus. To avoid a strong linkage between SNPs, we kept only the first SNP of each RAD locus. Further filtering was performed on the basis of minor allele frequency, missing data rates for both individuals (i.e the percentage of missing genotypes per individual) and loci (the percentage of non-genotyped individuals per locus), using VCFtools v0.1.17 (Danecek et al., 2011) (Table 1). We aimed to identify the signatures of clonality from putatively neutral loci. To this end, we excluded outlier loci identified as involved under divergent selection with pcadapt v3.5 (Luu et al., 2017). Pcadapt starts by analysing population structure with a PCA. Then candidate outliers are identified as those which are excessively correlated with population structure (Luu et al., 2017). The outlier identified with pcadapt should then correspond to inflated signals of genetic differentiation.

\section{The impact of SNP filtering on population genetic summary statistics}


RAD-seq is subject to different sources of genotyping errors (Mastretta-Yanes et al., 2015) that may generate spurious inferences in surveys of genetic variation. However, the noise of artifactual SNPs can be efficiently overcome by applying a rigorous filtering strategy of raw RAD-seq datasets (e.g. McKinney et al., 2017; O'Leary et al., 2018) and measuring its effects on population genetic summary statistics (Shafer et al., 2017). Care was taken in this study to minimize the impact of artifactual SNPs on the true biological signal of the datasets (see Supporting Information "Materials S1"). To achieve this, we studied the impact of different filtering cutoffs on several parameters of genetic diversity and departure from panmixia: i) the mean $\mathrm{F}_{\mathrm{IS}}$ and standard deviation (SD) among loci, ii) the overall $\mathrm{F}_{\mathrm{ST}}$ and SD among loci, iii) the SNP error rate, defined as the proportion of SNP mismatches between replicate pairs (Mastretta-Yanes et al., 2015). We have specifically explored the effect of the maximum rate of missing data allowed per SNP (max-missing), the minor allele frequency (MAF), and the mean read depth per locus across all individuals (meanDP), or by considering only loci for which genotypes were strictly identical between replicates. Further details are given in Supporting Information "Materials S1".

\section{Clonality in Laminaria rodriguezii}

Because of somatic mutations and sequencing errors, we do not expect to get two strictly identical genotypes over thousands of loci even if they belong to the same clonal lineage. Consequently, we considered that genotypes with very low divergence corresponded to the same clonal lineage. We chose the maximum distance between replicates $(d=0.022$ for $L$. rodriguezii, $\mathrm{d}=0.020$ for $L$. digitata, see Results) as a threshold to identify repeated genotypes. Distances were computed as the ratio of the number of allelic differences between two individuals (the Hamming distance, implemented in the function diss.dist of the Poppr v2.8.2 $R$ package). Samples of $L$. rodriguezii separated by a distance lower than the aforementioned threshold were clustered into clonal lineages (referred here as MLLs Multi-Locus Lineages, see Arnaud-Haond et al., 2007) using the UPGMA clustering algorithm (implemented in Poppr v2.8.2 R packages: Kamvar et al., 2014; Kamvar et al., 2015). The matrix of genetic distances was additionally used for the construction of a network with the neighbor-net method implemented in SplitsTree, which was used to visualize genetic proximity of samples from the same clonal lineages, and also the differences among populations (Huson, 1998). We 
computed the genotypic richness (R) index within populations (Dorken \& Eckert, 2001), as

follows: $R=\frac{G-1}{N-1}$, where $\mathrm{G}$ is the number of distinct genotypes detected in the population and $\mathrm{N}$ the total number of individuals sampled. We thus considered each cluster of clonal individuals as a single genotype to calculate $G$. The distribution of clonal membership was analysed with the Pareto $\beta$ index as described in Arnaud-Haond et al. (2007) using the Poppr v2.8.2 R package. Finally, the average values of genetic diversity and population differentiation of $L$. rodriguezii were estimated in two complementary ways: firstly, including all genotyped individuals, secondly by keeping only one representative of each clonal lineage.

\section{Genetic diversity}

The within-population genetic diversity was assessed with the datasets of $L$. rodriguezii and $L$. digitata, after the removal of potentially selected loci. Given that the percentage of polymorphic loci (\%P) may be affected by the variations in sample sizes, we used a random sampling approach implemented in a custom bash script (available at https://github.com/rebecca-ci/revegetation). The percentage of polymorphic loci was calculated from 100 random resamplings (with replacement between samples) for each sample size at the population level. In addition, estimates of observed heterozygosity $\left(H_{0}\right)$, expected heterozygosity $\left(H_{e}\right)$, and $F_{I S}$ (Weir \& Cockerham, 1984) were calculated with the GENEPOP v1.0.5 R package (Rousset, 2008). The same data sets were also analyzed with the HierFstat R package (Goudet, 2005) to compute the distribution of $F_{\text {IS }}$ values across loci. We used a two-sample Kolmogorov-Smirnov (KS) test to test for differences in the distribution of FIs between populations. We used the KS D statistic as the maximum distance between cumulative distributions to assess the magnitude of these differences. The P-value of the D statistic was computed using a bootstrapping method ( $10^{6}$ bootstraps), with the Matching v4.9.7 R package (Sekhon, 2008). The distributions were divided into ten discrete classes of $F_{I S}$ for which the frequency of occurrence in populations was shown as histograms. The Global Hardy-Weinberg test [Score (U) test] (Rousset \& Raymond, 1995), implemented in GENEPOP, was used to test departure from panmixia across all loci for the different populations. The test was performed twice: firstly by considering the alternative hypothesis of heterozygote excess and secondly by considering heterozygote deficiency. The P-value of each test was approximated by Markov chain (MCMC) algorithm with the following settings; 
dememorization: 10 000, batch: 100, iterations per batch: 10 000. Then, a multisample score test (Rousset \& Raymond, 1995) was performed to obtain a global P-value per population. Finally, the two-sided P-value of the Global Hardy-Weinberg test [Score (U) test] was obtained by computing the following formula: Pmin + (1 - Pmax) where Pmin and Pmax are the smaller and the higher probabilities of unilateral tests, respectively (De Meeûs, 2012). Linkage disequilibrium (LD) among loci was analyzed with the standardized index of multilocus association $\overline{\boldsymbol{r}_{\boldsymbol{d}}}$ (Agapow \& Burt, 2001) in Poppr v2.8.2. The $\overline{\boldsymbol{r}_{\boldsymbol{d}}}$ index is a summary statistic of linkage disequilibrium based on the variance of pairwise distances among individuals (see details in Agapow \& Burt, 2001). This index is particularly useful for datasets with a high number of loci for which pairwise approaches are difficult to apply. To avoid the consequences of a Wahlund effect, we computed the $\overline{\boldsymbol{r}_{\boldsymbol{d}}}$ index separately for each sampling site. Genotypes were permuted 1000 times among individuals inside populations to test for linkage disequilibrium.

\section{Population differentiation in Laminaria rodriguezii}

The overall level of genetic differentiation (overall FST $_{\text {ST }}$ was estimated in Genepop v4.2.2. We performed a G-based test of genotypic differentiation across loci (Goudet et al., 1996) with the same software. The P-value for each locus was computed using the Markov chain method with default parameters (500000 iterations). The significance of the test was evaluated by the method of the harmonic mean P-values (HMP) (Wilson, 2019), implemented in the harmonicmeanp v3 R package. The test compares $P_{R}$, the HMP of a set of P-values $R$, to $\alpha_{L}$, the significance threshold for a false positive rate weighted by $\omega_{R}$, the total number of individual P-values (see Table 1 in Wilson, 2019). The HMP P-value is significant when $P_{R} \leq$ $\alpha_{L} \omega_{R}$. We used a false positive rate of 0.05 and an equal weight for each P-value, considered as similar to Bonferroni correction.

\section{RESULTS}

\section{Sequencing and SNPs filtering}

Approximately 1.2 billion (1 154828457 ) raw reads were produced from 49 samples of $L$. rodriguezii (i.e. 47 individuals and two replicates) and 130 samples of L. digitata (i.e. 125 
individuals and five replicates). After quality filtering and read trimming, an average of 2.7 million ( \pm 1.5 million $\mathrm{SE}$ ) and 2.3 million ( \pm 2.1 million $\mathrm{SE}$ ) high-quality reads per individual were retained for $L$. rodriguezii and $L$. digitata, respectively. The percentage of reads mapped to the L. digitata genome, ranged from an average of $85.4 \%$ (min: 53.9\%; max: $92.2 \%$ ) for $L$. rodriguezii, to $94.2 \%$ (min: 67.9\%; max: $97.6 \%$ ) for L. digitata. The initial filtering of loci, which retained those shared by a high proportion of individuals, resulted in catalogs of 44716 loci and 60942 loci for L. rodriguezii and L. digitata, respectively. At this stage, the number of SNPs was more than eight times higher for $L$. digitata than for L. rodriguezii (Table 1). Additional quality filtering steps followed by outlier exclusion resulted in the selection of 4077 putatively neutral SNPs among 43 individuals of $L$. rodriguezii and 7364 putatively neutral SNPs among 116 individuals of L. digitata (Table 1). Specifically, 289 SNPs (6.62\%) and 174 SNPs (2.31\%) were identified as outliers for $L$. rodriguezii and L. digitata, respectively. The rate of missing data was slightly higher in L. digitata (i.e. 3.36\%) than in L. rodriguezii (i.e. 2.24\%). The mean SNP error rate across replicates was estimated to be $1.06 \%$ in L. digitata and $3.89 \%$ in $L$. rodriguezii datasets.

\section{Clonal structure of Laminaria rodriguezii}

In L. rodriguezii, the distribution of pairwise genetic distances was discontinuous with a gap from the threshold $d=0.022$ to the lowest distance reported above this threshold $(d=0.042)$ (Figure 2A). This threshold corresponded to the maximum distance observed among replicates. The use of this threshold allowed us to identify four different clonal lineages with several members: namely MLL-A, MLL-B, MLL-C and MLL-D, composed of three, three, seven, two samples respectively (see the network, Figure 3). By selecting only one sample for each clonal lineage, we finally retained 32 different samples in our data analyses from the 43 samples initially present in the whole dataset. At Bonifacio (Southern Corsica), we reported a relatively strong occurrence of clonal lineages $(R=0.20)$, with the dominance of a few large clones $(\beta=0.56)$, which contrasted with the low occurrence of clonal lineages $(R=0.90)$ of small size $(\beta=2.66)$ in Eastern Provence (Table S2, Supporting Information). For instance, the maximum clonal size reported was seven at Bonifacio against three in Eastern Provence. The analysis of the spatial genetic structure along the transect at Banc Magaud_2 (Figure S1, Supporting Information) revealed that: i) individuals belonging to the same clonal lineage were relatively close to one another (less than one meter) and ii) the genetic distance between 
individuals increased with spatial distance (Mantel test, $R=0.40, p<0.001$ ). For the other sites, the sampling protocol (with a minimum spacing of two meters), did not allow a similar investigation of the spatial genetic structure. Contrary to L. rodriguezii, no pairwise distance among distinct individuals of $L$. digitata was below the distance threshold defined by replicates (Figure $2 \mathrm{~B}$ ), indicating that there was no cluster of genotypes grouped in clonal lineages. The lowest divergence among individuals in L. digitata was around $d=0.035$, and corresponded to intra-population differences within the Helgoland population.

Besides the detection of clonal lineages, we observed in L. rodriguezii three individuals, with distinct long branches in the phylogenetic networks (indicated as outliers in Figure 3). These three outlier individuals shared a common characteristic: the highest proportion of heterozygous genotypes among loci per individual, with an average of $33 \%$ against $16 \%$ in other individuals (Figure S2, Supporting Information). These outlier individuals also had the highest percentage of private alleles among all individuals (average percentage of private alleles at the individual level $(\operatorname{Pr})=20.3 \%$ for outlier individuals and $\operatorname{Pr}=1.0 \%$ among the other 40 genotyped individuals, see Figure S2, Supporting Information). By definition, these private alleles were different among the three individuals.

\section{Genetic diversity}

Laminaria rodriguezii and Laminaria digitata displayed similar expected heterozygosity $\left(\mathrm{H}_{\mathrm{e}}\right)$, with an average $\mathrm{H}_{\mathrm{e}}$ within populations of 0.14 and 0.15 , respectively (Table 2). The proportion of polymorphic loci $(P)$ within populations (estimated with the minimum sampling size $n=10$ and 100 random resamples) was higher in L. rodriguezii (average $\mathrm{P}=54.42 \%$ ) than in L. digitata (average $\mathrm{P}=39.39 \%$ ) (see Table 2, Figure S3, Supporting Information). We observed a departure from panmixia in both species, with an excess of heterozygotes in L. rodriguezii, and a deficit of heterozygotes in L. digitata (see Table 3 for L. rodriguezii and Table S1, Supporting Information for L. digitata). The heterozygotes excess was statistically significant (Score [U] test, $\mathrm{P}<0.001)$ within populations for L. rodriguezii, except for Banc Magaud_1. The heterozygotes deficit was significant (Score $[U]$ test, $P<0.001$ ) within populations of $L$. digitata.

The distributions of $F_{I S}$ were significantly different for all intra and inter-specific comparisons of $L$. rodriguezii and L. digitata populations (KS tests, $p<0.001$, D statistic: $0.07-0.53$ ). At the intraspecific level, the most striking difference in the distributions of $F_{I S}$ (KS tests, D statistic: 
0.26-0.27) was detected for L. rodriguezii between Eastern Provence (Banc Magaud_1, Banc_Magaud_2 and Cap Camarat) and Bonifacio (Figure 4A). The distributions of FIs in Eastern Provence were moderately skewed to negative values with a long tail to positive values (skewness $=0.69$; kurtosis $=4.07$ ). The distribution of $F_{I S}$ in Bonifacio was highly skewed toward negative values (skewness $=-0.95$; kurtosis $=3.14$ ) and showed a much higher proportion of extreme negative values as above to $-0.8(13.6 \%)$ in comparison to those measured in Eastern Provence (average, 0.6\%). Similarly, the variance in $\mathrm{F}_{\text {IS }}$ among loci was higher at Bonifacio (var $=0.13$ ) than in Eastern Provence (var $=0.08,0.07$ and 0.06 for Banc Magaud_1, Banc Magaud_2, and Cap Camarat, respectively).

In contrast to these results, $F_{I S}$ values were mainly positive in L. digitata, whatever the population considered even if the distribution mode of $F_{I S}$ is always observed between -0.1 and 0 (Figure 4B). Extreme negative $F_{\text {IS }}$ (above -0.8 ) and even moderate to high negative values (those between -0.5 and -0.3 ) were almost absent in L. digitata with frequencies of $0.03 \%$ and $0.06 \%$, respectively. The distribution mode of $F_{I S}$ was observed for slightly negative values between -0.1 and 0 whatever the population considered (Figure 4B). The asymmetry of the distributions, as revealed by the positive skewness (skewness $=0.98$; kurtosis $=3.32$ ) is indicative of a long tail toward high and extreme positive values ( 0.5 to 1 ). This class of extreme positive $\mathrm{F}_{\mathrm{IS}}$ corresponded to $28 \%$ of all loci in Helgoland. At the intra-specific level, the second major difference in the shape of the distribution of $F_{I S}$ was reported between Helgoland and all other populations of $L$. digitata (KS tests, D statistic 0.11-0.23).

The average multilocus estimates of $F_{I S}$ within populations ranged from 0.12 to 0.43 for $L$. digitata (Table S1, Supporting Information) whereas mean values were mainly negative within populations in L. rodriguezii, with a range from -0.47 in Bonifacio to -0.02 at Banc Magaud_1 (Table 3A). After applying the correction for repeated genotypes, the average multilocus estimates of $F_{I S}$ increased to a range from $F_{I S}=-0.26$ at Bonifacio to $F_{I S}=-0.01$ at Banc Magaud_2 (Table 3B). After the correction for repeated genotypes, the heterozygosity excess only remained significant at Bonifacio (Score $[U]$ test, $\mathrm{P}<0.001$ ).

The distribution of the index of multilocus association $\overline{\boldsymbol{r}_{\boldsymbol{d}}}$ (Figure 5) was nearly identical whatever the number of SNPs subsampled (i.e. 1000; 2000 and 3000 random SNPs). The mean $\overline{\boldsymbol{r}_{\boldsymbol{d}}}$ was statistically significant $(\mathrm{p}<0.001)$ within all populations of both species. For $L$. rodriguezii, the $\overline{\boldsymbol{r}_{\boldsymbol{d}}}$ index reached high levels within all populations (mean $\overline{\boldsymbol{r}_{\boldsymbol{d}}}=0.08$ to 0.27 ), except at Banc Magaud_1 (mean $\overline{r_{\boldsymbol{d}}}=0.01$ ) for which there was no repeated sampling of a 
clonal lineage (Table 3). The values of $\overline{\boldsymbol{r}_{\boldsymbol{d}}}$ decreased slightly by keeping only one representative of each clonal lineage (Table 3, Figure 5). For L. digitata, the mean $\overline{\boldsymbol{r}_{\boldsymbol{d}}}$ ranged between 0.01 to 0.03 within all populations (Table S1, Figure 5), except for Helgoland that displayed a remarkably high level of linkage disequilibrium similar to values observed in $L$. rodriguezii (mean $\left.\overline{r_{d}}=0.20\right)$.

\section{Population differentiation in Laminaria rodriguezii}

Laminaria rodriguezii exhibited high levels of population structure with a global FST of 0.28 when considering all individuals $(n=43$ ). After applying the clone correction (i.e. one sample per clonal lineage), the estimate of genetic differentiation decreased (global $F_{S T}=0.18$ ). After correcting for multiple testing, genotypic differentiation among populations of L. rodriguezii was significant (HMP significance threshold, $\alpha_{L} \omega_{R}=0.032$; HMP P-value, $P_{R}=0$ ), with and without the clone correction.

\section{Negative $F_{I S}$ and high $F_{S T}$ in $L$. rodriguezii over SNP filtering methods}

For $L$. rodriguezii, the mean $F_{\text {IS }}$ and overall $F_{S T}$ varied between the reference dataset and the filtered datasets (Table 4). However, the mean FIs was always negative, with high variance among loci, whatever the levels of stringency. In the same way, the overall $\mathrm{F}_{\text {ST }}$ stayed high and it was never below 0.27 . The maximum rate of missing data allowed per SNP (max-missing) had a very limited effect on mean $F_{I S}$ and overall $F_{S T}$, which ranged from -0.06 to -0.07 and from 0.27 to 0.30 , respectively. The highest variance was associated with MAF cutoff as the filter excluded the lowest polymorphic loci, and subsequently increased the level of genetic variation in the dataset. Therefore, we choose to keep the MAF cutoff at $2 \%$ so as not to inflate the levels of genetic variation in L. rodriguezii. The SNP error rate decreased from $5.22 \%$ in the reference dataset to $2.74 \%$ in the dataset which was filtered by excluding loci with low coverage (i.e. meanDP > 15X). Genotyping errors were probably non-randomly distributed and occurred mostly in loci with low coverage, so we excluded them by applying meanDP > 15X. 
We used RAD-sequencing to analyze the genome-wide diversity of the rare Laminaria rodriguezii. We found that intra-individual genomic diversity is a powerful tool to identify clonal lineages. We also proposed that the observed $\mathrm{F}_{\mathrm{IS}}$ distribution and linkage disequilibrium at the genome scale can be compared with theoretical models to search for a discernable signal of clonality, even in this partially clonal reproducing species. Finally, we will discuss here the findings of high heterozygosity within some individuals that raise questions about the mechanisms allowing the persistence of such genomic features.

\section{RAD-seq as a powerful tool for detection of clonal lineages}

The identification of clonal lineages in natural populations was addressed by assessing the probability that identical or slightly distinct genotypes belong to the same clonal lineage. That can be achieved through the development of standardized methods allowing for investigation of the influence of somatic mutations and scoring errors (Arnaud-Haond et al., 2007). However, while this methodological framework is particularly robust for a small number of loci, RAD-seq and the amount of data generated by Next Generation Sequencing (NGS) brings new challenges. The main concern is that increasing the number of loci is equivalent to increasing the number of missing data and genotyping errors that can subsequently affect the detection of clonal lineages. This is especially the case for reduced representation sequencing (e.g. RAD-seq) sensitive to missing data and genotyping error, thus necessitating appropriate filtering strategy (e.g. Mastretta-Yanes et al., 2015; Shafer et al., 2017; Andrews et al., 2018; Boscari et al., 2019). How then can we find an adequate distance threshold for collapsing slightly distinct genotypes into clonal lineages? For that purpose, we can define a threshold using the pairwise genetic distances, a threshold below which genotypes are assumed to belong to the same clonal lineage. Some studies have fixed a cut-off based on the gap in pairwise genetic distances (e.g. Shrestha et al., 2014), while others have defined an arbitrary 95\% genotype similarity threshold (e.g. Locatelli \& Drew, 2019). Nevertheless, such approaches can be inaccurate, particularly when different sources of noise (i.e. genotyping error, missing data, somatic mutation) can accentuate differences between clonal genotypes above the detection threshold. This also depends on the genetic diversity of the populations: 
clonal lineages are more easily identified in populations where the diversity among sexually produced individuals is high, i.e. in partially clonal species. In this study, we proposed defining a threshold on the basis of the pairwise genetic distance across replicates. While this approach seems to be useful in evaluating the genetic distance expected as a result of genotyping errors and somatic mutations, it has rarely been reported, except in Leptopsammia pruvoti (Boscari et al., 2019). For this organism genotyped with 1386 SNPs (with the $2 b-R A D$ protocol), slightly distinct genotypes below a distance threshold set at $d=0.043$ were collapsed into clonal lineages. For $L$. rodriguezii, this cut-off was lower $(d=0.022)$, even if of a similar order as in $L$. pruvoti. This difference highlights the importance of not considering a common threshold but rather of adjusting it using genotype mismatch across replicates. Note that using the same method on both species, the threshold was very similar between L. rodriguezii and L. digitata.

\section{The genomic patterns of clonality}

Our results show how the distribution of $F_{\text {IS }}$ among loci can be used to study species and populations with various signals of clonality including partial clonality. Signatures of clonality in natural populations are usually inferred from repeated genotypes, along with mean negative values of $F_{I S}$, and linkage disequilibrium across loci (Balloux et al., 2003; Halkett et al., 2005). Nevertheless, recent studies reported that one of these signatures, genotypic richness, had poor relevance for measuring the relative importance of sexual versus clonal reproduction (Arnaud-Haond et al., 2020), even using relatively large sample sizes (from 100 to 500 individuals) (Stoeckel et al., 2019). This is because the estimates of genotypic richness are strongly dependent on sampling strategy and density, basically decreasing with increasing sampling effort (Arnaud-Haond et al., 2007; Gorospe et al., 2015; Becheler et al., 2017). In our study, by looking at the $F_{I S}$ distribution in the genome, we propose a new analysis which seems useful to detect partial clonal reproduction. Our approach confirmed the prediction that interlocus variance of $F_{\text {IS }}$ (rather than an average value) increased as clonal rates increased (Balloux et al., 2003; Halkett et al., 2005; Stoeckel \& Masson 2014; Reichel et al., 2016; Stoeckel et al., 2019). We also reported (1) contrasted distribution of $F_{I S}$ between species, with $F_{I S}$ shifted towards negative values in the partially clonal species L. rodriguezii, and towards positive values in the fully sexually reproducing species L. digitata; (2) striking differences in distributions of $F_{I S}$ among populations of $L$. rodriguezii, with higher inter-locus variance in $F_{\text {IS }}$ 
at Bonifacio (Corsica) than in the three localities of Eastern Provence. Remarkably, the empirical distributions of $F_{I S}$ in Eastern Provence matched well with the simulation results of Stoeckel \& Masson (2014) which predicted that most $F_{I S}$ values are concentrated between 0.3 and 0.1 below intermediate levels of clonality.

Genetic drift is another possible explanation for negative $F_{I S}$ values. In a finite population with random mating, genetic drift due to sampling effect indeed tends to create a slightly negative mean $F_{I S}$, but the effect is small, of order $1 /(2 N)$ where $N$ is the size of the population (see Figures 3 and 4 in Stoeckel \& Masson, 2014). For the fully sexual dioicous species L. digitata, this drift effect could explain why the distribution mode of $F_{I S}$ is between -0.1 and 0 whatever the population considered. However, the probability of highly negative values increases when genetic drift is combined with intermediate rates of clonality (Stoeckel \& Masson, 2014). Nevertheless, Stoeckel \& Masson (2014) showed that values below -0.3 remain rare if the clonality rate is below 0.9 . This is indeed what is observed for all L. rodriguezii populations, suggesting that their clonality rates are intermediate, except at Bonifacio, the Corsican population for which we observed the highest proportion of $F_{I S}$ below -0.3 and even below 0.8. In addition, the estimates of genotypic richness (R), Pareto $(\beta)$, and linkage disequilibrium $\left(\overline{r_{d}}\right)$ emphasized the degree of distinction between the Eastern Provence and Bonifacio populations, thus strengthening our hypothesis of a higher level of clonality in Corsica than in Eastern Provence. A more in-depth investigation of the combined effects of drift and clonal reproduction on the distribution of $F_{I S}$ would be useful in this context. Parameters other than reproductive mode differ between the two species compared here, such as the levels of genetic drift, the investigated geographical range, and potentially their demographic history. The population of Helgoland for the fully sexually reproducing species, L. digitata, reached a high level of linkage disequilibrium comparable to the Bonifacio population of $L$. rodriguezii for which the signature of clonality was clearly discernible. Nevertheless, Helgoland had a distribution of $F_{I S}$ markedly different from L. rodriguezii, with a majority of positive values. Helgoland is a rocky island surrounded by several hundreds of kilometers of sandy seafloor. This population shows the highest levels of positive $F_{I S}$, the lowest values of pairwise genetic distances between individuals, and the highest value of linkage genetic disequilibrium observed for L. digitata. This is most probably explained by the effect of low effective size and maybe of a bottleneck. This population also showed the lowest level of genetic diversity observed for L. digitata when genotyped with the microsatellite locus in the study of Liesner 
et al. (2020). There is a lack of case studies to conclude more precisely on the role of drift and of demographic history in the distribution of inter locus $F_{\text {IS }}$ variance. However, the theoretical results of Stoeckel \& Masson (2014) and Stoeckel et al. (2019) agree well with our experimental results. This paves the way toward a better assessment of the importance of clonality through genomic studies, but it remains the case that the estimation of clonality rates is still only possible using temporal sampling (Ali et al., 2016; Becheler et al., 2017).

\section{Extreme levels of individual genomic heterozygosity}

We reported an intriguing signal of genome-wide heterozygosity in three of the 43 individuals in L. rodriguezii. These outlier individuals were characterized by an exceptionally high proportion of heterozygous genotypes compared to other individuals. Given the relatively low sample sizes, we do not really know how these individuals depart from the population distribution in individual heterozygosity, but we can discuss several hypotheses regarding their origin. High heterozygosity at particular loci can correspond to paralogs assembled in the same RAD locus depending on assembly parameters (Verdu et al., 2016; Mckinney et al., 2017; Nadukkalam Ravindran et al., 2018). However, for the following reasons, we would argue that polymorphisms detected within these outlier individuals do not correspond to artefactual loci: firstly, sequencing reads were mapped to the reference genome of a closely related species, followed by stringent filter criteria, including for maximum heterozygosity. Secondly, pairedend sequencing protocols provide additional information on correct read placement since RAD loci are retained when both reads are properly mapped (according to the insert length between forward and reverse reads). Thirdly, if paralogs were responsible for high levels of heterozygosity, we would not expect to observe this in only three individuals. On the other hand, recent studies have revealed that both cross-contamination among samples and environmental contamination, especially during library preparation and/or sequencing, can lead to artifactual results, with the sequencing of loci of different origins in the same sample (Laurin-Lemay et al., 2012; Ballenghien et al., 2017). Here, the three outlier individuals were also characterised by the highest proportion of private alleles at the individual level, and they were not grouped on the network. Such private alleles can then not be explained by crosscontamination among samples of the same species. Rather they could be explained by the accumulation of mutations along with clonal reproduction, thus increasing the divergence among loci in the same individuals, a potential signal of the Meselson effect (Birky, 1996; 
Welsh \& Meselson, 2000; De Meeûs et al., 2007). These outlier individuals could then belong to a relatively ancient asexual lineage. However, we lack temporal sampling to get more precise estimates of the rates of clonal reproduction, and therefore, the hypothesis of clonality to explain these outlier individuals remains highly speculative. A high frequency of heterozygous loci could also be observed following hybridization among well differentiated genetic lineages. Hybridization has indeed been proposed as the main driver of high heterozygosity in parthenogenetic animals (Jaron et al., 2020). Here, the hybrid hypothesis should involve several hybridizations from three different sources to explain the observed pattern of private alleles, as well as the genetic distance among the three outliers. It would therefore be interesting to analyze the genomic diversity of other $L$. rodriguezii populations in the Mediterranean in order to go further on this topic. Nevertheless, the populations of $L$. rodriguezii are scarce, and there are no other congeneric species in this area.

\section{Implications for conservation}

Our results emphasise that $L$. rodriguezii is spatially structured into genetically distinct populations. At Banc Magaud_2 we also evidenced a significant spatial genetic structure: regarding the low occurrence of clonality in this population, this structure is better explained by reduced dispersal through haploid spores. Although high levels of population genetic structure are not uncommon in kelps (e.g. Billot et al., 2003; Coleman et al., 2009; Durrant et al., 2018), our results contrast with the lack of genetic differentiation among populations of $L$. digitata spatially distant by up to $10 \mathrm{~km}$ (Billot et al., 2003; Robuchon et al., 2014). In this respect, the spatial scale of dispersal of $L$. rodriguezii is presumably smaller than that reported in other species of the genus Laminaria (Santelices, 1991). The patchy distribution and small population sizes of $L$. rodriguezii can probably explain this pattern of high and local genetic differentiation through strong local genetic drift and limited gene flow among populations. The identification of such a local genetic structure has important implications for management and conservation. The high genetic drift and limited gene flow can explain the lower genetic diversity expected in L. rodriguezii compared to L. digitata, a species with a wider geographical distribution, exhibiting semi-continuous and dense populations (see Hamrick \& Godt, 1990; Frankham, 1996; Levy et al., 2016). Furthermore, the range of L. rodriguezii has been drastically reduced during the last half-century, especially in the Adriatic Sea, where the species has suffered losses of $85 \%$ from its historical range (Žuljević et al., 2016). However, the 
observed heterozygosity and the percentage of polymorphic loci were higher in L. rodriguezii when compared to L. digitata. This can be explained by the conservation of heterozygous genotypes with low recombination rates (Judson \& Normark, 1996; Balloux et al., 2003; see Meloni et al., 2013 for an empirical example), as genetic drift under clonal reproduction acts on genotype frequencies rather than allele frequencies (Stoeckel \& Masson, 2014; Reichel et al., 2016). Further studies would be necessary to test with genomic data whether the current fragmented range and small populations of $L$. rodriguezii correspond to a demographic reduction from a larger ancestral population. The extensive cartography and monitoring of the biocenoses down to $100 \mathrm{~m}$ along French coasts do point to the rarity of this species. The conservation of these last isolated populations should become a high priority for stakeholders.

\section{Conclusion}

Our study shows that despite limitations on the detection of clonal lineages, SNPs derived from RAD sequencing are interesting markers for population genomic studies of partially clonal species. The interaction between demographic history and reproductive mode shaped the distribution of $F_{I S}$ and linkage disequilibrium in L. rodriguezii. Interestingly, even if our loci were mapped to a reference genome for assembly, we did not use the physical location of loci in our analyses, which indicates that similar approaches could be envisioned with de novo assembly. In order to decipher the respective impact of demography and reproduction in our results, one next step could be to use summary statistics linked with these distributions (such as higher moments) for evolutionary inferences, using for example Approximate Bayesian Computation (Csilléry et al., 2010). 
This project was funded, by the MARFOR Biodiversa/0004/2015 project (http://marfor.eu/), and by the Agence Nationale de la Recherche, Grant/ Award Number: ANR-18-CE32-0001 (Clonix2D). Lauric Reynes also received support from the GDR Génomique Environnementale (GDR3692). The project leading to this publication has received funding from the European FEDER Fund under project 1166-39417. This work was also funded by a Ph.D. Fellowship from Région PACA and the Calanques National Park. The authors would like to thank Julie Deter, in charge of the scientific coordination during sampling, the team of research divers of Andromède Océanologie for the prowess in sampling Laminaria rodriguezii at 76 meters depth, the Biogenouest genomics core facility (Genomer Plateforme génomique at the Station Biologique de Roscoff) for their technical support, Claire Daguin-Thiébaut and Quentin Langevin for useful discussions regarding the optimization processes in purpose-extracted

603

604

605

606

607

608

609

610

611

612

613 high-quality DNA in brown macroalgae, Marck Cock providing the draft genome of Laminaria digitata, Thierry Gosselin for very useful discussions on the quality control of RADseq data, and finally Solenn Stoeckel for his comments on the manuscript. We deeply thank Thierry De Meeûs, three anonymous reviewers and the corresponding editor, Tatiana Giraud, for their comments that enabled us to greatly improve the current version of this manuscript. Finally, we would like to thank Michael Paul for English language proofreading.

09 
[dataset] Reynes, L., Thibaut, T., Mauger, S., Blanfuné, A., Holon, F., Cruaud, C., ... Aurelle, D. (2020). Individual high-quality reads (dd-RADsequencing) "Genomic signatures of clonality in the deep water kelp Laminaria rodriguezii". Dryad. doi:10.5061/dryad.hmgqnk9dq

Adjeroud, M., Guérécheau, A., Vidal-Dupiol, J., Flot, J.-F., Arnaud-Haond, S., \& Bonhomme, F. (2014). Genetic diversity, clonality and connectivity in the scleractinian coral Pocillopora damicornis: a multi-scale analysis in an insular, fragmented reef system. Marine Biology, 161(3), 531-541. doi: 10.1007/s00227-013-2355-9

Agapow, P.-M., \& Burt, A. (2001). Indices of multilocus linkage disequilibrium. Molecular Ecology Notes, 1(1-2), 101-102. doi: 10.1046/j.1471-8278.2000.00014.x

Alberto, F., Gouveia, L., Arnaud-Haond, S., Perez-Llorens, J. L., Duarte, C. M., \& Serrao, E. A. (2005). Within-population spatial genetic structure, neighbourhood size and clonal subrange in the seagrass Cymodocea nodosa. Molecular Ecology, 14(9), 2669-2681. doi: 10.1111/j.1365-294X.2005.02640.x

Ali, S., Soubeyrand, S., Gladieux, P., Giraud, T., Leconte, M., Gautier, A., ... Enjalbert, J. (2016). Cloncase: Estimation of sex frequency and effective population size by clonemate resampling in partially clonal organisms. Molecular Ecology Resources, 16(4), 845861. doi: 10.1111/1755-0998.12511

Andrew, S. (2010). FastQC: a quality control tool for high throughput sequence data. (Version 0.11.7). Retrieved from http://www.bioinformatics.babraham.ac.uk/projects/fastqc

Andrews, K. R., Adams, J. R., Cassirer, E. F., Plowright, R. K., Gardner, C., Dwire, M., ... Waits, L. P. (2018). A bioinformatic pipeline for identifying informative SNP panels for parentage assignment from RADseq data. Molecular Ecology Resources, 18(6), 12631281. doi: 10.1111/1755-0998.12910

Araújo, R. M., Assis, J., Aguillar, R., Airoldi, L., Bárbara, I., Bartsch, I., ... Sousa-Pinto, I. (2016). Status, trends and drivers of kelp forests in Europe: an expert assessment. Biodiversity and Conservation, 25(7), 1319-1348. doi: 10.1007/s10531-016-1141-7 Ardehed, A., Johansson, D., Schagerström, E., Kautsky, L., Johannesson, K., \& Pereyra, R. T. (2015). Complex spatial clonal structure in the macroalgae Fucus radicans with both sexual and asexual recruitment. Ecology and Evolution, 5(19), 4233-4245. doi: 10.1002/ece3.1629

Arnaud-Haond, S., Migliaccio, M., Diaz-Almela, E., Teixeira, S., Van De Vliet, M. S., Alberto, F., ... Serrão, E. A. (2007). Vicariance patterns in the Mediterranean Sea: east-west cleavage and low dispersal in the endemic seagrass Posidonia oceanica. Journal of Biogeography, 34(6), 963-976. doi: 10.1111/j.1365-2699.2006.01671.x

Arnaud-Haond, S., Duarte, C. M., Alberto, F., \& Serrao, E. A. (2007). Standardizing methods to address clonality in population studies. Molecular ecology, 16(24), 5115-5139. doi: 10.1111/j.1365-294X.2007.03535.x

Arnaud-Haond, S., Stoeckel, S., \& Bailleul, D. (2020). New insights into the population genetics of partially clonal organisms: when seagrass data meet theoretical expectations. Molecular Ecology, mec.15532. doi: 10.1111/mec.15532

Baird, N. A., Etter, P. D., Atwood, T. S., Currey, M. C., Shiver, A. L., Lewis, Z. A., ... Johnson, E. A. (2008). Rapid SNP discovery and genetic mapping using sequenced RAD markers. 
PLOS ONE, 3(10), e3376. doi: 10.1371/journal.pone.0003376

Ballenghien, M., Faivre, N., \& Galtier, N. (2017). Patterns of cross-contamination in a multispecies population genomic project: detection, quantification, impact, and solutions. BMC Biology, 15(1), 25. doi: 10.1186/s12915-017-0366-6

Ballesteros, E. (2006). Mediterranean coralligenous assemblages: a synthesis of present knowledge. Oceanography and Marine Biology: An Annual Review, 44, 123-195.

Balloux, F., Lehmann, L., \& De Meeûs, T. (2003). The Population Genetics of Clonal and Partially Clonal Diploids. Genetics Society of America, 164(4), 1635-1644.

consequences of a major earthquake on asexual and sexual populations. Evolutionary Applications. doi: 10.1111/eva.12967

Becheler, R., Masson, JP., Arnaud-Haond, S., Halkett, F., Mariette, S., Guillemin, ML., ... Stoeckel, S. (2017). ClonEstiMate, a Bayesian method for quantifying rates of clonality of populations genotyped at two-time steps. Molecular Ecology Resources, 17(6), e251-e267. doi: 10.1111/1755-0998.12698

Becheler, R., Guillemin, M.-L., Stoeckel, S., Mauger, S., Saunier, A., Brante, A., ... Valero, M. (2020). After a catastrophe, a little bit of sex is better than nothing: Genetic

Beichman, A. C., Koepfli, K.-P., Li, G., Murphy, W., Dobrynin, P., Kliver, S., ... Wayne, R. K. (2019). Aquatic Adaptation and Depleted Diversity: A Deep Dive into the Genomes of the Sea Otter and Giant Otter. Molecular Biology and Evolution, 36(12), 2631-2655. doi: $10.1093 / \mathrm{molbev} / \mathrm{msz101}$

Billot, C., Engel-Gautier, C., Rousvoal, S., Kloareg, B., \& Valero, M. (2003). Current patterns, habitat discontinuities and population genetic structure: the case of the kelp Laminaria digitata in the English Channel. Marine Ecology Progress Series, 253, 111121. doi: $10.3354 /$ meps 253111

Bringloe, T. T., Starko, S., Wade, R. M., Vieira, C., Kawai, H., Clerck, O. D., ... Verbruggen, H. (2020). Phylogeny and Evolution of the Brown Algae. Critical Reviews in Plant Sciences, 39(4), 281-321. doi: 10.1080/07352689.2020.1787679

Birky, C. W. (1996). Heterozygosity, heteromorphy, and phylogenetic trees in asexual eukaryotes. Genetics,144(1), 427-437.

Bolger, A. M., Lohse, M., \& Usadel, B. (2014). Trimmomatic: a flexible trimmer for Illumina sequence data. Bioinformatics, 30(15), 2114-2120. doi: 10.1093/bioinformatics/btu170

Boscari, E., Abbiati, M., Badalamenti, F., Bavestrello, G., Benedetti-Cecchi, L., Cannas, R., ... Congiu, L. (2019). A population genomics insight by $2 b-R A D$ reveals populations' uniqueness along the Italian coastline in Leptopsammia pruvoti (Scleractinia, Dendrophylliidae). Diversity and Distributions, 25(7), 1101-1117. doi: 10.1111/ddi.12918

Catchen, J. M., Amores, A., Hohenlohe, P., Cresko, W., \& Postlethwait, J. H. (2011). Stacks: Building and Genotyping Loci De Novo From Short-Read Sequences. G3: Genes, Genomes, Genetics, 1(3), 171-182. doi: 10.1534/g3.111.000240

Coleman, M. A., Gillanders, B. M., \& Connell, S. D. (2009). Dispersal and gene flow in the habitat-forming kelp, Ecklonia radiata: relative degrees of isolation across an eastwest coastline. Marine and Freshwater Research, 60(8), 802-809. doi: 10.1071/MF08268

Coleman, M., \& Wernberg, T. (2018). Genetic and morphological diversity in sympatric kelps with contrasting reproductive strategies. Aquatic Biology, 27, 65-73. doi: 10.3354/ab00698 

Computation $(A B C)$ in practice. Trends in Ecology \& Evolution, 25(7), 410-418. doi: 10.1016/j.tree.2010.04.001

Danecek, P., Auton, A., Abecasis, G., Albers, C. A., Banks, E., DePristo, M. A., ... Durbin, R. (2011). The variant call format and VCFtools. Bioinformatics, 27(15), 2156-2158. doi: 10.1093/bioinformatics/btr330

Davey, J. W., Hohenlohe, P. A., Etter, P. D., Boone, J. Q., Catchen, J. M., \& Blaxter, M. L. (2011). Genome-wide genetic marker discovery and genotyping using nextgeneration sequencing. Nature Reviews Genetics, 12(7), 499-510. doi: $10.1038 / \mathrm{nrg} 3012$

De Meeûs, T., Lehmann, L., \& Balloux, F. (2006). Molecular epidemiology of clonal diploids: A quick overview and a short DIY (do it yourself) notice. Infection, Genetics and Evolution, 6(2), 163-170. doi: 10.1016/j.meegid.2005.02.004

De Meeûs, T., Prugnolle, F., \& Agnew, P. (2007). Asexual reproduction: Genetics and evolutionary aspects. Cellular and Molecular Life Sciences, 64(11), 1355-1372. doi: 10.1007/s00018-007-6515-2

De Meeûs, T. (2012). Initiation à la génétique des populations naturelles: Applications aux parasites et à leurs vecteurs. IRD Editions.

Demes, K. W., \& Graham, M. H. (2011). Abiotic Regulation of Investment in Sexual Versus Vegetative Reproduction in the Clonal Kelp Laminaria Sinclairii (laminariales, Phaeophyceae)1. Journal of Phycology, 47(3), 463-470. doi: 10.1111/j.15298817.2011.00981.x

Dorken, M. E., \& Eckert, C. G. (2001). Severely reduced sexual reproduction in northern populations of a clonal plant, Decodon verticillatus (Lythraceae). Journal of Ecology, 89(3), 339-350. doi: 10.1046/j.1365-2745.2001.00558.x

Duminil, J., Fineschi, S., Hampe, A., Jordano, P., Salvini, D., Vendramin, G. G., \& Petit, R. J. (2007). Can Population Genetic Structure Be Predicted from Life-History Traits? The American Naturalist, 169(5), 662-672. doi: 10.1086/513490

Durrant, H. M. S., Barrett, N. S., Edgar, G. J., Coleman, M. A., \& Burridge, C. P. (2018). Seascape habitat patchiness and hydrodynamics explain genetic structuring of kelp populations. Marine Ecology Progress Series, 587, 81-92. doi: 10.3354/meps12447

Ercegović, A. (1960). Quelques traits caracteristiques de la végétation des algues de I'Adriatique. Acta Botanica Croatica, 18-19.

Frankham, R. (1996). Relationship of Genetic Variation to Population Size in Wildlife. Conservation Biology, 10(6), 1500-1508. doi: 10.1046/j.1523-1739.1996.10061500.x

Goecke, F., Klemetsdal, G. and Ergon, Å. (2020). Cultivar Development of Kelps for Commercial Cultivation-Past Lessons and Future Prospects. Frontiers in Marine Science 7, 110.

González de León, S., Herrera, I., \& Guevara, R. (2016). Mating system, population growth, and management scenario for Kalanchoe pinnata in an invaded seasonally dry tropical forest. Ecology and Evolution, 6(13), 4541-4550. doi: 10.1002/ece3.2219

Gorospe, K. D., Donahue, M. J., \& Karl, S. A. (2015). The importance of sampling design: spatial patterns and clonality in estimating the genetic diversity of coral reefs. Marine Biology, 162(5), 917-928. doi: 10.1007/s00227-015-2634-8

Goudet, J., Raymond, M., De Meeûs, T., \& Rousset, F. (1996). Testing differentiation in diploid populations. Genetics, 144(4), 1933-1940. doi: 10.1093/genetics/144.4.1933 
Goudet, J. (2005). Hierfstat, a package for $r$ to compute and test hierarchical F-statistics. Molecular Ecology Notes, 5(1), 184-186. doi: 10.1111/j.1471-8286.2004.00828.x

Guillemin, M.-L., Faugeron, S., Destombe, C., Viard, F., Correa, J. A., \& Valero, M. (2008). Genetic variation in wild and cultivated populations of the haploid-diploid red alga Gracilaria chilensis: how farming practices favor asexual reproduction and heterozygosity. Evolution, 62(6), 1500-1519. doi: 10.1111/j.1558-5646.2008.00373.x

Halkett, F., Plantegenest, M., Prunier-Leterme, N., Mieuzet, L., Delmotte, F., \& Simon, J. C. (2005). Admixed sexual and facultatively asexual aphid lineages at mating sites: admixed sexual and asexual lineages in aphids. Molecular Ecology, 14(1), 325-336. doi: 10.1111/j.1365-294X.2004.02358.x

Halkett, F., Simon, J.-C., \& Balloux, F. (2005). Tackling the population genetics of clonal and partially clonal organisms. Trends in Ecology \& Evolution, 20(4), 194-201. doi: 10.1016/j.tree.2005.01.001

Hamrick, J. L., \& Godt, M. J. W. (1990). Allozyme diversity in plant species. Plant Population Genetics, Breeding, and Genetic Resources., 43-63.

Huson, D. H. (1998). SplitsTree: analyzing and visualizing evolutionary data. Bioinformatics. 14(1), 68-73. doi: 10.1093/bioinformatics/14.1.68

Huvé, H. (1955). Présence de Laminaria rodriguezii Bornet sur les cotes françaises de la Méditerranée. Recueil Des Travaux de La Station Marine d'Endoume, 15.

Jaron, K. S., Bast, J., Nowell, R. W., Ranallo-Benavidez, T. R., Robinson-Rechavi, M., \& Schwander, T. (2020). Genomic features of parthenogenetic animals. BioRxiv doi: 10.1101/497495

Judson, O. P., \& Normark, B. B. (1996). Ancient asexual scandals. Trends in Ecology \& Evolution, 11(2), 41-46. doi: 10.1016/0169-5347(96)81040-8

Kamvar, Z. N., Brooks, J. C., \& Grünwald, N. J. (2015). Novel R tools for analysis of genomewide population genetic data with emphasis on clonality. Frontiers in Genetics, 6. doi: 10.3389/fgene.2015.00208

Kamvar, Z. N., Tabima, J. F., \& Grünwald, N. J. (2014). Poppr: an R package for genetic analysis of populations with clonal, partially clonal, and/or sexual reproduction. PeerJ, 2, e281. doi: 10.7717/peerj.281

Kettenring, K. M., \& Mock, K. E. (2012). Genetic diversity, reproductive mode, and dispersal differ between the cryptic invader, Phragmites australis, and its native conspecific. Biological Invasions, 14(12), 2489-2504. doi: 10.1007/s10530-012-0246-5

Koffi, M., Meeûs, T. D., Bucheton, B., Solano, P., Camara, M., Kaba, D., ... Jamonneau, V. (2009). Population genetics of Trypanosoma brucei gambiense, the agent of sleeping sickness in Western Africa. Proceedings of the National Academy of Sciences, 106(1), 209-214. doi: 10.1073/pnas.0811080106

Laurin-Lemay, S., Brinkmann, H., \& Philippe, H. (2012). Origin of land plants revisited in the light of sequence contamination and missing data. Current Biology, 22(15), R593R594. doi: 10.1016/j.cub.2012.06.013

Le Cam, S., Daguin-Thiébaut, C., Bouchemousse, S., Engelen, A. H., Mieszkowska, N., \& Viard, F. (2019). A genome-wide investigation of the worldwide invader Sargassum muticum shows high success albeit (almost) no genetic diversity. Evolutionary Applications, 13(3), 500-514. doi: 10.1111/eva.12837

Levy, E., Byrne, M., Coates, D. J., Macdonald, B. M., McArthur, S., \& van Leeuwen, S. (2016). Contrasting Influences of Geographic Range and Distribution of Populations on 
Patterns of Genetic Diversity in Two Sympatric Pilbara Acacias. PLoS ONE, 11(10). doi: 10.1371/journal.pone.0163995

Li, H., \& Durbin, R. (2009). Fast and accurate short read alignment with Burrows-Wheeler transform. Bioinformatics, 25(14), 1754-1760. doi: 10.1093/bioinformatics/btp324

Liesner, D., Fouqueau, L., Valero, M., Roleda, M. Y., Pearson, G. A., Bischof, K., ... Bartsch, I. (2020). Heat stress responses and population genetics of the kelp Laminaria digitata (Phaeophyceae) across latitudes reveal differentiation among North Atlantic populations. Ecology and Evolution, 10(17), 9144-9177. doi: 10.1002/ece3.6569

Locatelli, N., \& Drew, J. (2019). Population structure and clonal prevalence of scleractinian corals (Montipora capitata and Porites compressa) in Kaneohe Bay, Oahu. BioRxiv doi: 10.1101/2019.12.11.860585

Luu, K., Bazin, E., \& Blum, M. G. B. (2017). pcadapt: an R package to perform genome scans for selection based on principal component analysis. Molecular Ecology Resources, 17(1), 67-77. doi: 10.1111/1755-0998.12592

Marshall, D. R., \& Weir, B. S. (1979). Maintenance of genetic variation in apomictic plant populations. Heredity, 42(2), 159-172. doi: 10.1038/hdy.1979.20

Mastretta-Yanes, A., Arrigo, N., Alvarez, N., Jorgensen, T. H., Piñero, D., \& Emerson, B. C. (2015). Restriction site-associated DNA sequencing, genotyping error estimation and de novo assembly optimization for population genetic inference. Molecular Ecology Resources, 15(1), 28-41. doi: 10.1111/1755-0998.12291

McKinney, G. J., Waples, R. K., Seeb, L. W., \& Seeb, J. E. (2017). Paralogs are revealed by proportion of heterozygotes and deviations in read ratios in genotyping-bysequencing data from natural populations. Molecular Ecology Resources, 17(4), 656669. doi: 10.1111/1755-0998.12613

Meloni, M., Reid, A., Caujapé-Castells, J., Marrero, Á., Fernández-Palacios, J. M., Mesa-Coelo, R. A., \& Conti, E. (2013). Effects of clonality on the genetic variability of rare, insular species: the case of Ruta microcarpa from the Canary Islands. Ecology and Evolution, 3(6), 1569-1579. doi: 10.1002/ece3.571

Nadukkalam Ravindran, P., Bentzen, P., Bradbury, I. R., \& Beiko, R. G. (2018). PMERGE: Computational filtering of paralogous sequences from RAD-seq data. Ecology and Evolution, 8(14), 7002-7013. doi: 10.1002/ece3.4219

Nebavi, F., Ayala, F. J., Renaud, F., Bertout, S., Eholie, S., Moussa, K., ... De Meeûs, T. (2006). Clonal population structure and genetic diversity of Candida albicans in AIDS patients from Abidjan (Cote d'Ivoire). Proceedings of the National Academy of Sciences, 103(10), 3663-3668. doi: 10.1073/pnas.0511328103

Nougué, O., Rode, N. O., Jabbour-zahab, R., Ségard, A., Chevin, L.-M., Haag, C. R., \& Lenormand, T. (2015). Automixis in Artemia: Solving a century-old controversy. Journal of Evolutionary Biology, 28(12), 2337-2348. doi: 10.1111/jeb.12757

O'Leary, S. J., Puritz, J. B., Willis, S. C., Hollenbeck, C. M., \& Portnoy, D. S. (2018). These aren't the loci you'e looking for: Principles of effective SNP filtering for molecular ecologists. Molecular Ecology, 27(16), 3193-3206. doi: https://doi.org/10.1111/mec.14792

Omilian, A. R., Cristescu, M. E. A., Dudycha, J. L., \& Lynch, M. (2006). Ameiotic recombination in asexual lineages of Daphnia. Proceedings of the National Academy of Sciences, 103(49), 18638-18643. doi: 10.1073/pnas.0606435103

Pardo, C., Guillemin, M.-L., Peña, V., Bárbara, I., Valero, M., \& Barreiro, R. (2019). Local 
Coastal Configuration Rather Than Latitudinal Gradient Shape Clonal Diversity and Genetic Structure of Phymatolithon calcareum Maerl Beds in North European Atlantic. Frontiers in Marine Science, 6, 149. doi: 10.3389/fmars.2019.00149

Peterson, B. K., Weber, J. N., Kay, E. H., Fisher, H. S., \& Hoekstra, H. E. (2012). Double Digest RADseq: An Inexpensive Method for De Novo SNP Discovery and Genotyping in Model and Non-Model Species. PLoS ONE, 7(5). doi: 10.1371/journal.pone.0037135 Raymond, M., \& Rousset, F. (1995). An Exact Test for Population Differentiation. Evolution, 49(6), 1280-1283. doi: https://doi.org/10.1111/j.1558-5646.1995.tb04456.x

Reichel, K., Masson, J.-P., Malrieu, F., Arnaud-Haond, S., \& Stoeckel, S. (2016). Rare sex or out of reach equilibrium? The dynamics of FIS in partially clonal organisms. BMC Genetics, 17(1), 76. doi: 10.1186/s12863-016-0388-z

Robuchon, M., Le Gall, L., Mauger, S. and Valero, M. 2014. Contrasting genetic diversity patterns in two sister kelp species co-distributed along the coast of Brittany, France. Molecular Ecology 23:2669-2685. doi:10.1111/mec.12774

Rochette, N. C., Rivera-Colón, A. G., \& Catchen, J. M. (2019). Stacks 2: Analytical methods for paired-end sequencing improve RADseq-based population genomics. Molecular Ecology, 28(21), 4737-4754. doi: 10.1111/mec.15253

Rousset, F., \& Raymond, M. (1995). Testing heterozygote excess and deficiency. Genetics, $140(4), 1413-1419$.

Rousset, François. (2008). genepop'007: a complete re-implementation of the genepop software for Windows and Linux. Molecular Ecology Resources, 8(1), 103-106. doi: 10.1111/j.1471-8286.2007.01931.x

Santelices, B. (1990). Patterns of reproduction, dispersal and recruitment in seaweeds. Oceanography and Marine Biology, 28, 177-276.

Schaefer, I., Domes, K., Heethoff, M., Schneider, K., Schon, I., Norton, R. A., ... Maraun, M. (2006). No evidence for the "Meselson effect" in parthenogenetic oribatid mites (Oribatida, Acari). Journal of Evolutionary Biology, 19(1), 184-193. doi: 10.1111/j.1420-9101.2005.00975.x

Schwander, T., Henry, L., \& Crespi, B. J. (2011). Molecular Evidence for Ancient Asexuality in Timema Stick Insects. Current Biology, 21(13), 1129-1134. doi: 10.1016/j.cub.2011.05.026

Schwander, T. (2016). Evolution: The end of an ancient asexual scandal. Current Biology, 26(6), 233-235. doi: 10.1016/j.cub.2016.01.034

Sekhon, J. S. (2008). Multivariate and propensity score matching software with automated balance optimization: The Matching package for R (SSRN Scholarly Paper No. ID 1009044). Rochester, NY: Social Science Research Network.

Shafer, A. B. A., Peart, C. R., Tusso, S., Maayan, I., Brelsford, A., Wheat, C. W., \& Wolf, J. B. W. (2017). Bioinformatic processing of RAD-seq data dramatically impacts downstream population genetic inference. Methods in Ecology and Evolution, 8(8), 907-917. doi: https://doi.org/10.1111/2041-210X.12700

Shrestha, S., Hu, J., Fryxell, R. T., Mudge, J., \& Lamour, K. (2014). SNP markers identify widely distributed clonal lineages of Phytophthora colocasiae in Vietnam, Hawaii and Hainan Island, China. Mycologia, 106(4), 676-685. doi: 10.3852/13-165

Stoeckel, S., \& Masson, J.-P. (2014). The Exact Distributions of FIS under Partial Asexuality in Small Finite Populations with Mutation. PLOS ONE, 9(1). doi: 
900

901

902

903

904

905

906

907

908

909

910

911

912

913

914

915

916

917

10.1371/journal.pone.0085228

Stoeckel, S., Porro, B., \& Arnaud-Haond, S. (2019). The discernible and hidden effects of clonality on the genotypic and genetic states of populations: improving our estimation of clonal rates. arXiv, 1902.09365, ver. 4 peer-reviewed and recommended by Peer Community in Evolutionary Biology. https://arxiv.org/abs/1902.09365v4 submitted to Molecular Eciology Resources

Verdu, C. F., Guichoux, E., Quevauvillers, S., De Thier, O., Laizet, Y., Delcamp, A., ... Mariette, S. (2016). Dealing with paralogy in RADseq data: in silico detection and single nucleotide polymorphism validation in Robinia pseudoacacia L. Ecology and Evolution, 6(20), 7323-7333. doi: 10.1002/ece3.2466

Weir, W., Capewell, P., Foth, B., Clucas, C., Pountain, A., Steketee, P., ... MacLeod, A. (2016). Population genomics reveals the origin and asexual evolution of human infective trypanosomes. ELife, 5, e11473. doi: 10.7554/eLife.11473

Weir, B. S., \& Cockerham, C. C. (1984). Estimating f-statistics for the analysis of population structure. Evolution, 38(6), 1358-1370. doi: 10.1111/j.1558-5646.1984.tb05657.x

Wilson, D. J. (2019). The harmonic mean $p$-value for combining dependent tests. Proceedings of the National Academy of Sciences, 116(4), 1195-1200. doi: 10.1073/pnas.1814092116

Žuljević, A., Peters, A. F., Nikolić, V., Antolić, B., Despalatović, M., Cvitković, I., ... Küpper, F. C. (2016). The Mediterranean deep-water kelp Laminaria rodriguezii is an endangered species in the Adriatic Sea. Marine Biology, 163(4), 69. doi: 10.1007/s00227-0162821-2 
920 Individual high-quality reads (dd-RADseq) that support the findings of this study are openly

921 available in a Dryad Digital Repository (doi:10.5061/dryad.hmgqnk9dq). The home-made 922 scripts used to generate the distribution of $F_{I S}$ values into classes, the histograms of pairwise 923 genetic distances, and the graphs representing the percentage of polymorphic loci are 924 available in the public repository: https://github.com/LauricReynes

\section{AUTHOR CONTRIBUTION}

Thierry Thibaut and Didier Aurelle devised the project and were responsible for the main conceptual ideas. Florian Holon performed the sampling of Laminaria rodriguezii. Aurélie Blanfuné contributed to sample preparation. Stéphane Mauger and Lauric Reynes performed the RAD-sequencing experiment and analyzed sequencing reads. Corinne Cruaud and Arnaud Couloux provided the draft genome of Laminaria digitata. Lauric Reynes performed research, analyzed data, and wrote the manuscript in close collaboration with Didier Aurelle and Myriam Valero. All authors provided critical feedback and helped to shape the research, analysis, and manuscript. 
Table 1. Quality filters used to build the final RAD-seq datasets of Laminaria rodriguezii and Laminaria digitata. For each filtering step, the number of SNP passing the filter (SNPs count), as well as the mean missing data rate per individual (missingness) and the mean sequencing depth per individual (coverage) are reported. Loci were initially built in both species from the draft genome of L. digitata using the Stacks v.2.4 bioinformatics pipeline. The threshold of missing genotypes per individual $<30 \%$ has deleted four and nine individuals in L. rodriguezii and $L$. digitata datasets respectively. See Methods for details.

Table 2. Comparison of population genetic summary statistics (mean and range of values) in Laminaria rodriguezii and Laminaria digitata. \% , average percentage of polymorphic loci within populations rarified at $n=10$ by random resampling (see methods for details), $H_{0}$, observed heterozygosity, $\mathrm{H}_{\mathrm{e}}$, expected heterozygosity, $\mathrm{F}_{\mathrm{IS}}$, fixation index.

Table 3. Genetic variation within populations of Laminaria rodriguezii (A) before and (B) after applying the clonal correction. Clonal correction consists of keeping only one representative of clonal lineages. $\mathrm{N}$, number of individuals successfully genotyped, $\mathrm{H}_{\mathrm{o}}$, observed heterozygosity, $\mathrm{H}_{\mathrm{e}}$, expected heterozygosity, $\mathrm{F}_{\mathrm{IS}}$, fixation index, $\overline{\boldsymbol{r}_{\boldsymbol{d}}}$, average multilocus linkage disequilibrium. $\mathrm{F}_{\mathrm{IS}}$ and $\overline{\boldsymbol{r}_{\boldsymbol{d}}}$ values highlighted in bold indicate significant heterozygote excess within populations $(P$-val $<0.001)$ and significant linkage disequilibrium ( $P$-val $<0.001)$, respectively.

Table 4. The effect of SNP filtering cutoffs on the mean $( \pm S D) F_{1 S}$ over loci, overall $( \pm S D) F_{S T}$ over loci and the SNP error rate in Laminaria rodriguezii. As thresholds, we considered the maximum rate of missing data allowed per SNP (max-missing), the Minor Allele Frequency (MAF), the mean read depth per locus across all individuals (meanDP). For each cutoff value we reported the number of SNP passing the filter (SNPs count), the mean missing data rate per individual (missingness), and the mean read depth per individual (coverage). We considered an additional set of SNPs (matching genotypes) for which replicates have exactly the same multi-locus genotypes (SNP error rate $=0$ ). 
979 Figure 1. Sampling map of Laminaria rodriguezii in Eastern Provence and Southern Corsica, 980 reporting the depth in meters of sampling sites and the number of individuals sampled per 981 site (N).

982

983

984

985

986

987

988

989

990

991

992

993

994

995

996

997

998

999

1000

1001

1002

1003

1004

1005

1006

1007

1008

1009

Figure 2. Frequency of pairwise genetic distances between individuals of (A) Laminaria rodriguezii and (B) Laminaria digitata. Intra-populational (Intra-pop), inter-populational (Inter-pop), within Helgoland (Intra-Hel) and replicates (Replicates) comparisons are colored according to the legend. The frequency of pairwise genetic distances across replicates was multiplied by 40 to create an optimum bin size. The vertical dotted line shows the distance threshold $(d=0.022)$ as reported as the maximum value of replicate pairs.

Figure 3. Phylogenetic networks of Laminaria rodriguezii represented with the neighbor-net method. Each dot represents an individual, Individuals belonging to the same clone (MLLs, Multi-Locus Lineages) are colored according to the legend. Individuals characterized by the highest proportion of heterozygous genotypes and private alleles are indicated as outliers.

Figure 4. Distributions of the fixation index $F_{I S}$ among loci within populations of (A) Laminaria rodriguezii and (B) Laminaria digitata computed across 4077 and 7364 putatively neutral SNPS, respectively. The $F_{I S}$ values were distributed into 10 discrete classes and the number of occurrences for each class is indicated on top of histogram bars. The variance of $F_{15}$ among loci (Var) is indicated in brackets next to population labels.

Figure 5. Distributions of the standardized index of multilocus association $\overline{\boldsymbol{r}_{\boldsymbol{d}}}$ within populations of Laminaria rodriguezii before (highlighted in red) and after (highlighted in green) clonal correction (cc). Comparison of the index value was done with five populations of Laminaria digitata (highlighted in blue). The $\overline{\boldsymbol{r}_{\boldsymbol{d}}}$ values were estimated using 10000 iterations by random subsampling of 1000; 2000 and 3000 SNPs. The abbreviations used for populations are those reported in Table 3 for L. rodriguezii and Table S1 for L. digitata. . 
Table 1

\begin{tabular}{|c|c|c|c|c|c|c|c|c|c|c|c|c|}
\hline & \multicolumn{3}{|c|}{$\% \mathrm{P}$} & \multicolumn{3}{|c|}{$\mathbf{H}_{\mathbf{o}}$} & \multicolumn{3}{|c|}{$\mathrm{H}_{\mathrm{e}}$} & \multicolumn{3}{|c|}{$F_{\text {IS }}$} \\
\hline \multicolumn{13}{|c|}{ L. rodriguezii } \\
\hline Average & \multicolumn{3}{|c|}{54.42} & \multicolumn{3}{|c|}{0.16} & \multicolumn{3}{|c|}{0.14} & \multicolumn{3}{|c|}{-0.14} \\
\hline Range & 40.96 & - & 72.14 & 0.11 & - & 0.19 & 0.11 & - & 0.18 & -0.47 & - & -0.02 \\
\hline \multicolumn{13}{|c|}{ L. digitata } \\
\hline Average & \multicolumn{3}{|c|}{39.39} & \multicolumn{3}{|c|}{0.11} & \multicolumn{3}{|c|}{0.15} & \multicolumn{3}{|c|}{0.26} \\
\hline Range & 21.44 & - & 54.89 & 0.09 & - & 0.14 & 0.12 & - & 0.19 & 0.12 & - & 0.43 \\
\hline
\end{tabular}

1012

1013

1014

1015 
Table 2

1017

\begin{tabular}{|c|c|c|c|c|c|c|}
\hline \multirow[b]{2}{*}{ Filtering thresholds } & \multicolumn{3}{|c|}{ Laminaria rodriguezii } & \multicolumn{3}{|c|}{ Laminaria digitata } \\
\hline & $\begin{array}{l}\text { SNP } \\
\text { counts }\end{array}$ & missingness & coverage & $\begin{array}{l}\text { SNP } \\
\text { counts }\end{array}$ & missingness & coverage \\
\hline $\begin{array}{l}\text { Locus genotyped } \\
>75 \% \text { of the samples } \\
>75 \% \text { of the populations } \\
\text { SNP kept } \\
\text { observed heterozygosity }<80 \%\end{array}$ & 70026 & $13.97 \%$ & 11.29 & 609699 & $12.26 \%$ & 14.11 \\
\hline $\begin{array}{l}\text { Linkage disequilibrium } \\
\text { single SNP per locus }\end{array}$ & 27769 & $13.18 \%$ & 11.88 & 58830 & $13.45 \%$ & 14.36 \\
\hline $\begin{array}{l}\text { Minor Allele Frequency (MAF) } \\
\text { MAF }>2 \%\end{array}$ & 16865 & $13.51 \%$ & 12.18 & 21090 & $15.01 \%$ & 14.43 \\
\hline $\begin{array}{l}\text { Missingness } \\
\text { per individual }<30 \% \\
\text { per SNP }<20 \%\end{array}$ & 13235 & $4.46 \%$ & 13.91 & 15150 & $4.73 \%$ & 17.24 \\
\hline $\begin{array}{l}\text { Coverage } \\
\text { mean read depth }>15 X \\
\text { mean read depth }<100 X\end{array}$ & 4366 & $2.27 \%$ & 22.17 & 7538 & $3.40 \%$ & 21.63 \\
\hline $\begin{array}{l}\text { Outliers detection } \\
\text { putatively neutral }\end{array}$ & 4077 & $2.29 \%$ & 22.04 & 7364 & $3.39 \%$ & 21.64 \\
\hline
\end{tabular}
1018

1019

1020

1021

1022

1023

1024

1025

1026

1027

1028

1029

1030

1031

1032

1033 
Table 3

\begin{tabular}{|c|c|c|c|c|c|c|}
\hline \multicolumn{7}{|c|}{ (A) } \\
\hline Population & Label & $\mathbf{N}$ & Ho & $\mathrm{He}$ & $F_{\text {IS }}$ & $\overline{r_{d}}$ \\
\hline Banc Magaud_1 & BM_1 & 10 & 0.18 & 0.17 & -0.02 & 0.01 \\
\hline Banc Magaud_2 & BM_2 & 11 & 0.19 & 0.18 & -0.04 & 0.08 \\
\hline Cap Camarat & CAM & 11 & 0.11 & 0.11 & -0.05 & 0.10 \\
\hline Bonifacio & BON & 11 & 0.16 & 0.11 & -0.47 & 0.27 \\
\hline \multicolumn{7}{|c|}{ (B) } \\
\hline Population & Label & $\mathbf{N}$ & $\mathrm{H}_{\mathrm{o}}$ & $\mathrm{He}_{\mathrm{e}}$ & $F_{\text {IS }}$ & $\overline{r_{d}}$ \\
\hline Banc Magaud_1 & BM_1 & 10 & 0.18 & 0.17 & -0.02 & 0.01 \\
\hline Banc Magaud_2 & BM_2 & 9 & 0.19 & 0.19 & -0.01 & 0.05 \\
\hline Cap Camarat & CAM & 10 & 0.11 & 0.11 & -0.02 & 0.10 \\
\hline Bonifacio & BON & 3 & 0.20 & 0.16 & -0.26 & 0.20 \\
\hline
\end{tabular}

1035

1036 


\section{Table 4}

\begin{tabular}{|c|c|c|c|c|c|c|c|}
\hline Quality filter & cutoff & SNPs count & missingness (\%) & coverage & mean $( \pm S D) F_{I S}$ & overall ( \pm SD) $F_{S T}$ & SNP error rate (\%) \\
\hline Reference dataset & & 21357 & 4.11 & 13.00 & $-0.07(0.20)$ & $0.27(0.18)$ & 5.22 \\
\hline \multirow{4}{*}{ max-missing (\%) } & $<15$ & 21114 & 3.97 & 13.08 & $-0.07(0.20)$ & $0.27(0.18)$ & 5.17 \\
\hline & $<10$ & 19468 & 3.33 & 13.52 & $-0.07(0.20)$ & $0.27(0.18)$ & 4.94 \\
\hline & $<5$ & 14480 & 1.95 & 14.88 & $-0.07(0.19)$ & $0.28(0.18)$ & 4.30 \\
\hline & 0 & 5479 & 0.00 & 18.12 & $-0.06(0.18)$ & $0.30(0.19)$ & 2.90 \\
\hline \multirow{3}{*}{ MAF (\%) } & $>2$ & 12735 & 4.28 & 13.31 & $-0.08(0.26)$ & $0.30(0.22)$ & 7.07 \\
\hline & $>5$ & 5094 & 4.54 & 16.18 & $-0.12(0.34)$ & $0.37(0.26)$ & 4.92 \\
\hline & $>10$ & 3428 & 4.56 & 17.29 & $-0.14(0.37)$ & $0.42(0.26)$ & 3.86 \\
\hline \multirow{3}{*}{ meanDP $(X)$} & $>5$ & 19245 & 3.59 & 13.71 & $-0.08(0.20)$ & $0.28(0.18)$ & 4.88 \\
\hline & $>10$ & 11773 & 2.52 & 17.41 & $-0.11(0.22)$ & $0.31(0.21)$ & 3.92 \\
\hline & $>15$ & 6163 & 1.90 & 21.85 & $-0.13(0.23)$ & $0.33(0.22)$ & 2.74 \\
\hline \multirow{4}{*}{$\begin{array}{l}\text { max-missing cutoff for } \\
\text { fixed MAF }(2 \%) \text { and } \\
\text { meanDP }(>15)\end{array}$} & $<20$ & 3911 & 2.14 & 21.83 & $-0.15(0.29)$ & $0.34(0.25)$ & 3.71 \\
\hline & $<10$ & 3850 & 1.99 & 21.81 & $-0.14(0.28)$ & $0.35(0.25)$ & 3.70 \\
\hline & $<5$ & 3464 & 1.41 & 21.90 & $-0.12(0.28)$ & $0.35(0.25)$ & 3.53 \\
\hline & 0 & 1813 & 0.00 & 22.71 & $-0.10(0.27)$ & $0.37(0.26)$ & 2.68 \\
\hline matching genotypes & & 3638 & 2.14 & 22.07 & $-0.15(0.29)$ & $0.35(0.25)$ & 0.00 \\
\hline
\end{tabular}




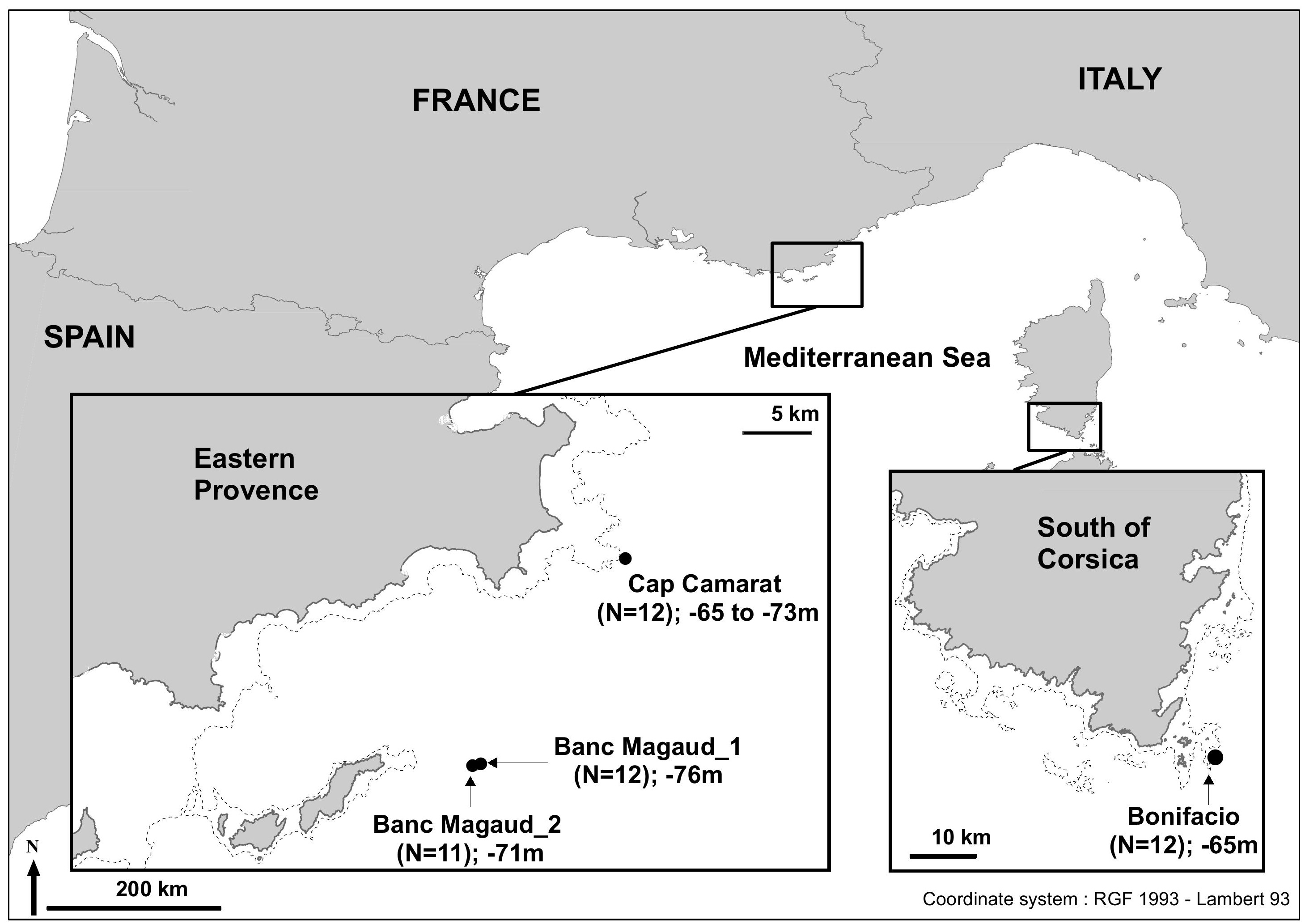




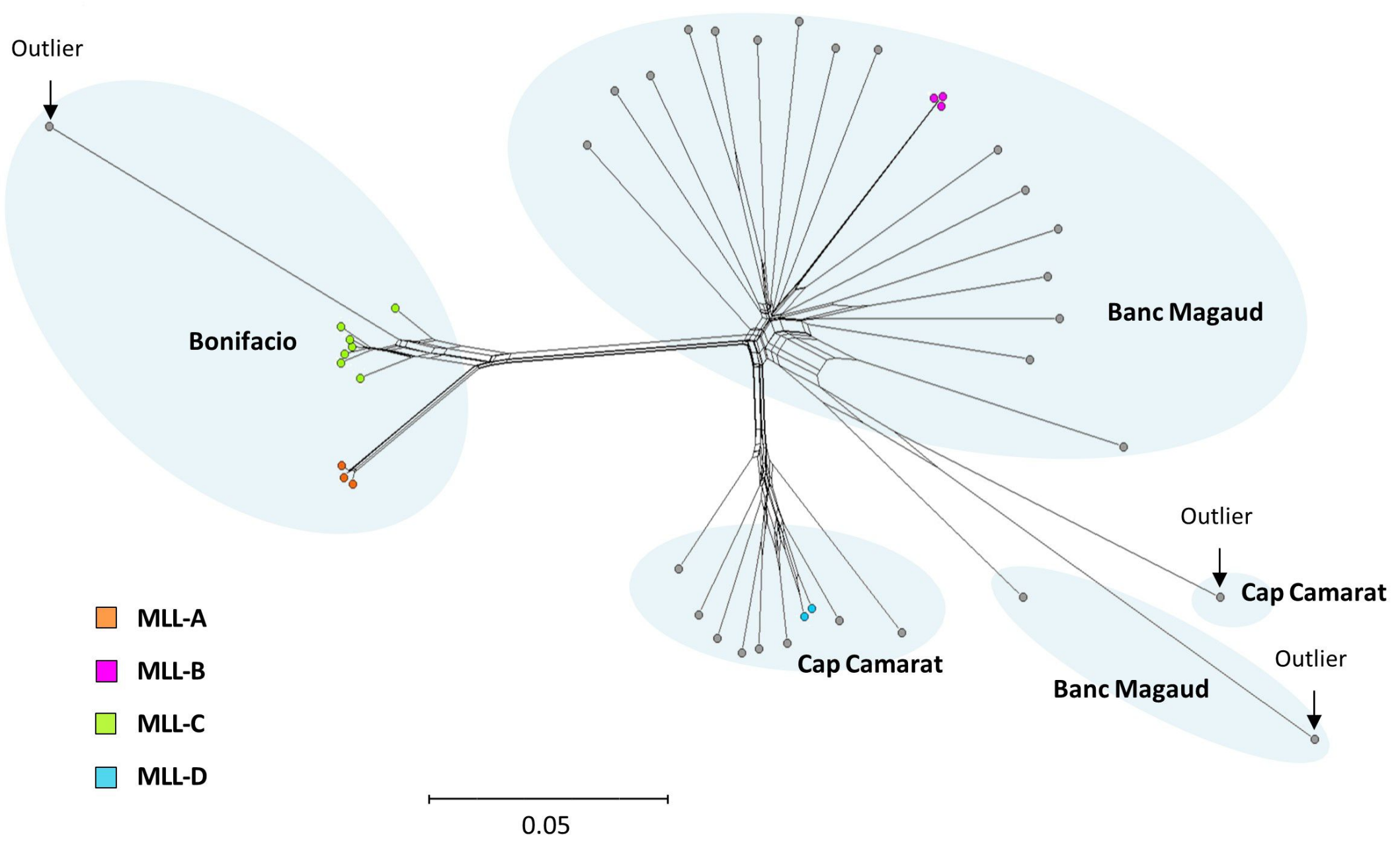



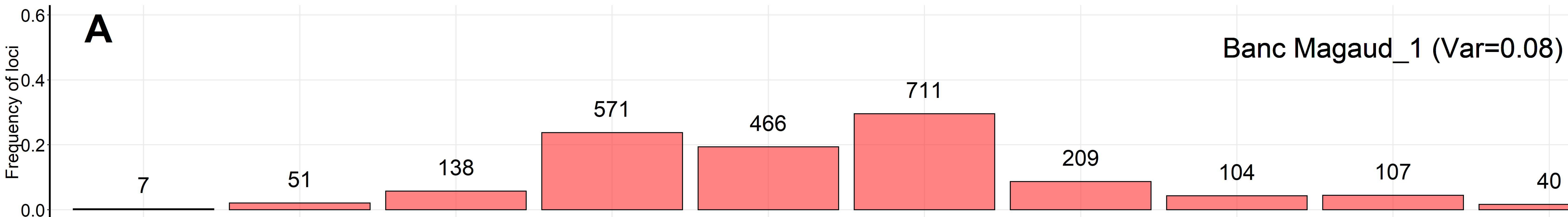

209

$[-0.1,0.0[\quad$ FIS

$[0.0,0.1[$

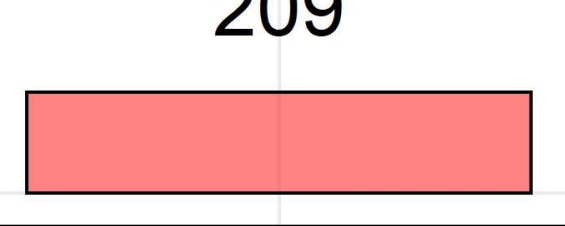

104
$\begin{array}{r}107 \\ \hline[0.5,0.8[\end{array}$ 40

$[-0.3,-0.1[$

$[0.1,0.3[$

$[0.3,0.5[$

Banc Magaud_2 (Var=0.07)

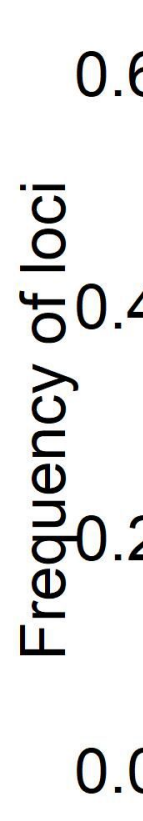

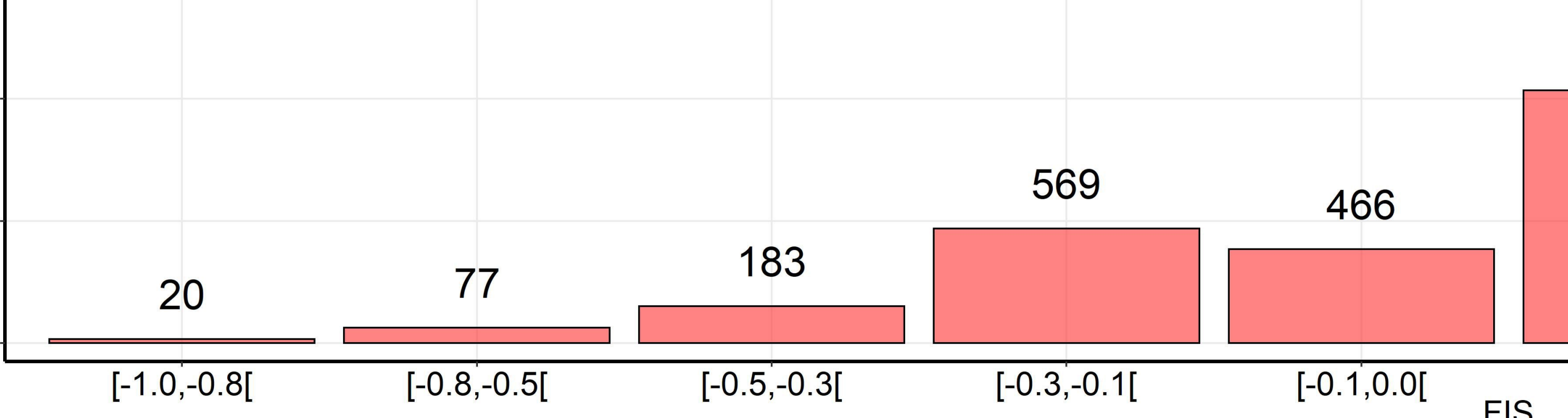

1256

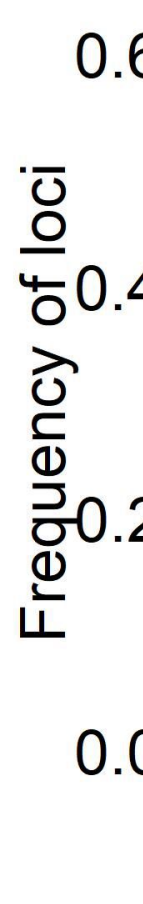

$[-0.5,-0.3[$

$[-0.1,0.0[\quad$ FIS

$[0.0,0.1[$
1057
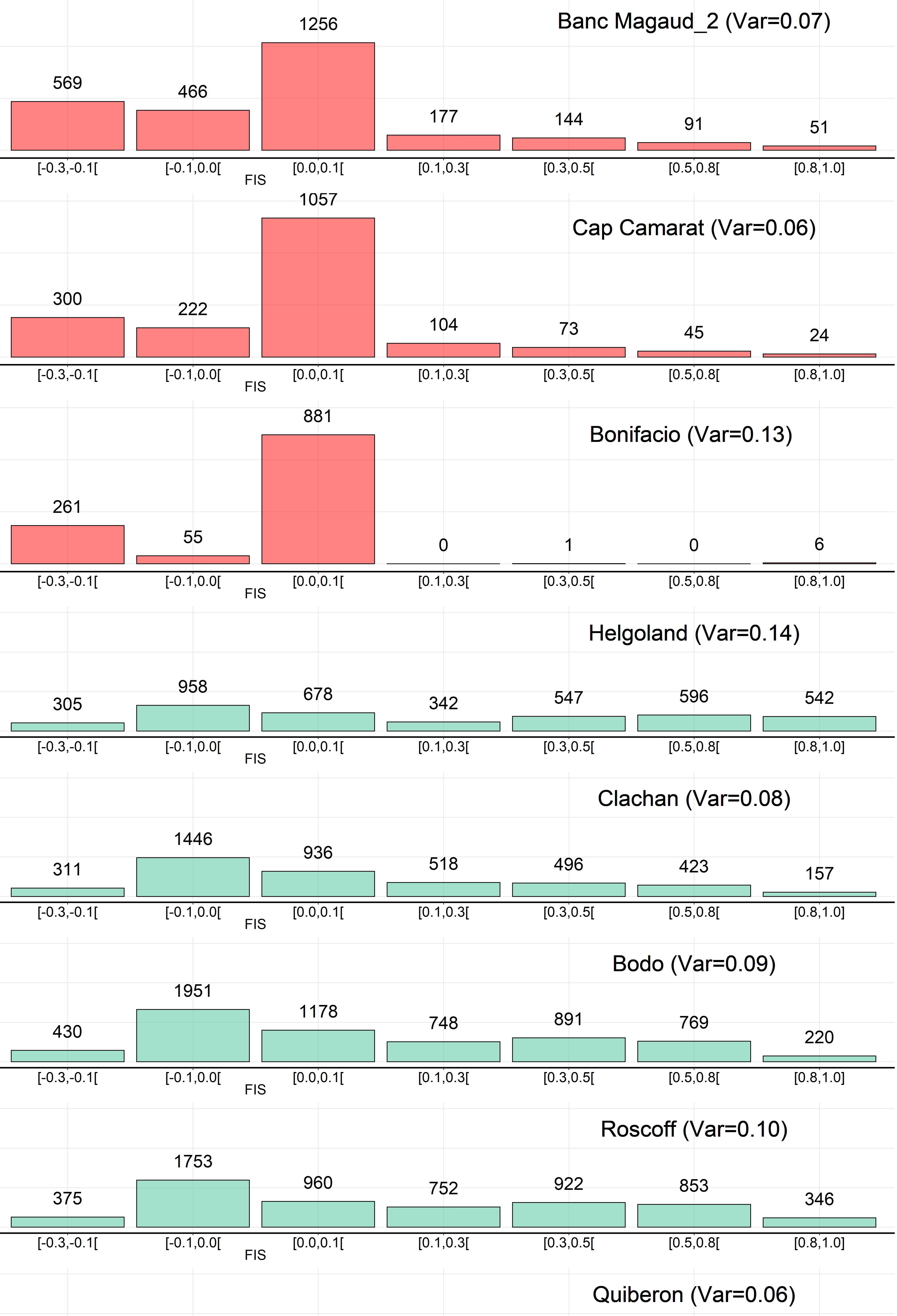

44

91

1

51

$[0.3,0.5[\quad[0.5,0.8[$

$[0.8,1.0]$

Cap Camarat (Var=0.06)

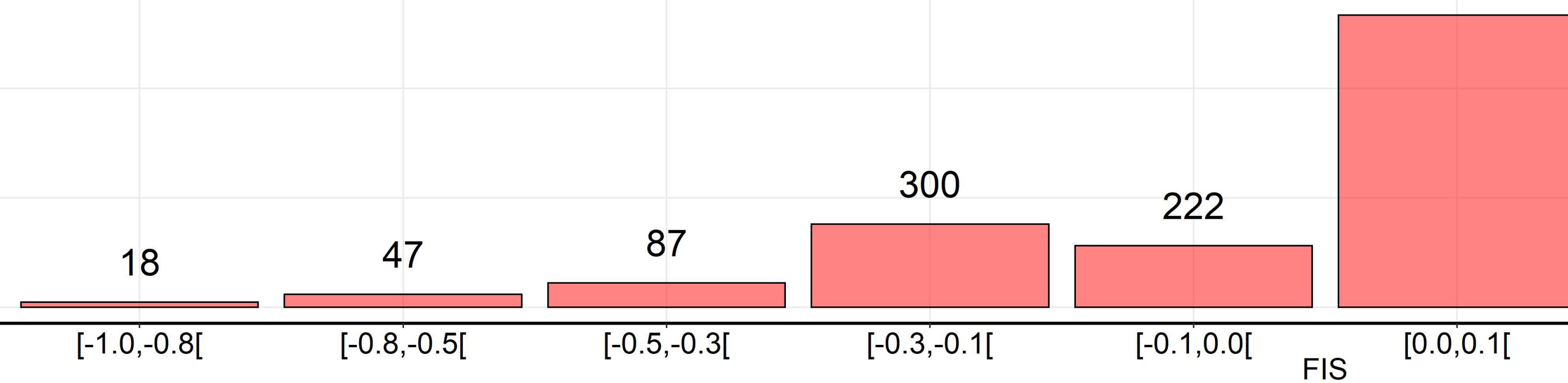

881
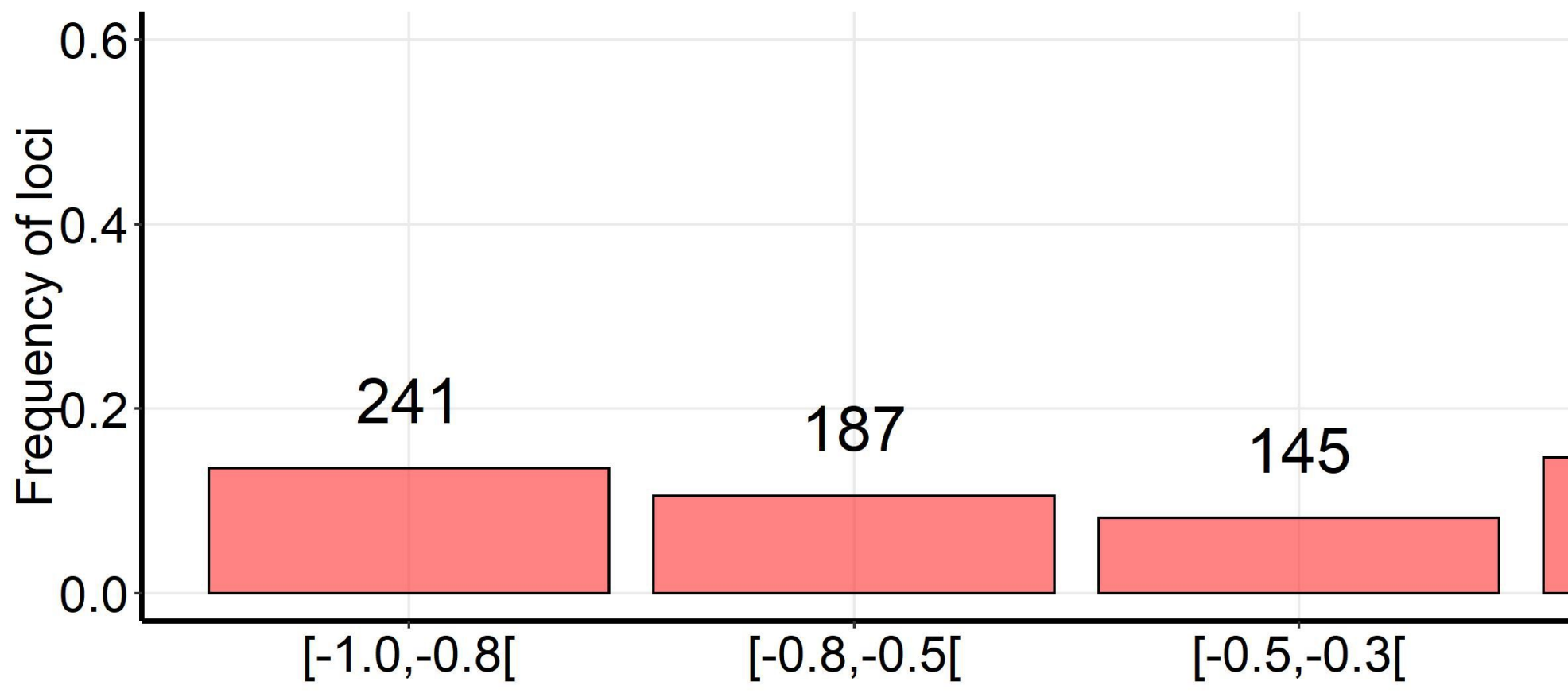

261

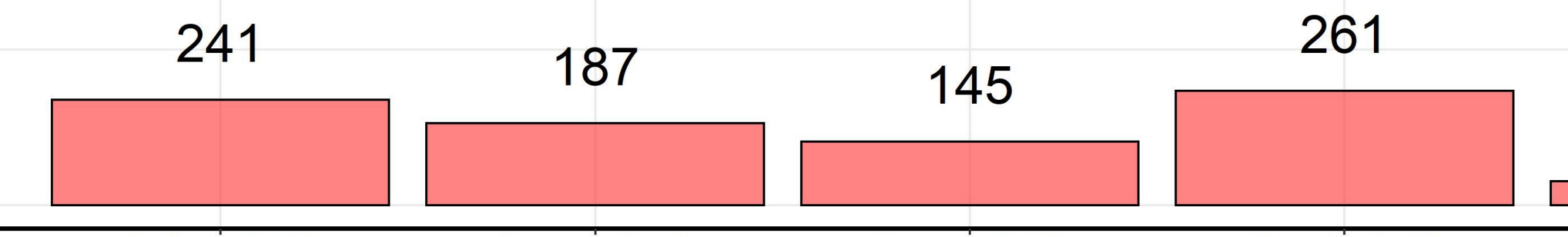

$[-1.0,-0.8[$

$[-0.8,-0.5[$

$[-0.3,-0.1[$

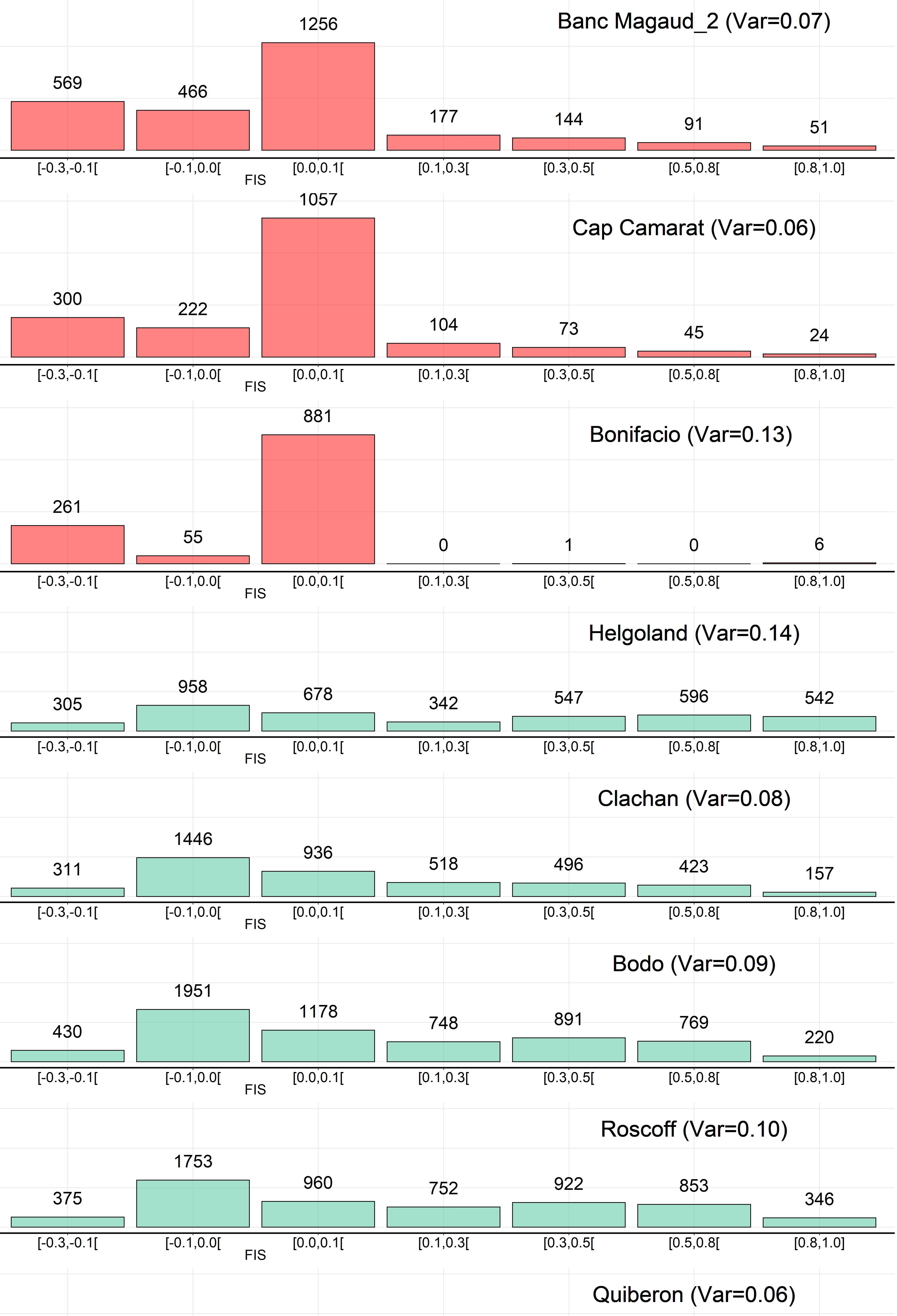

FIS $\quad[0.0,0.1[$

$\frac{0}{10.1,0.3}$
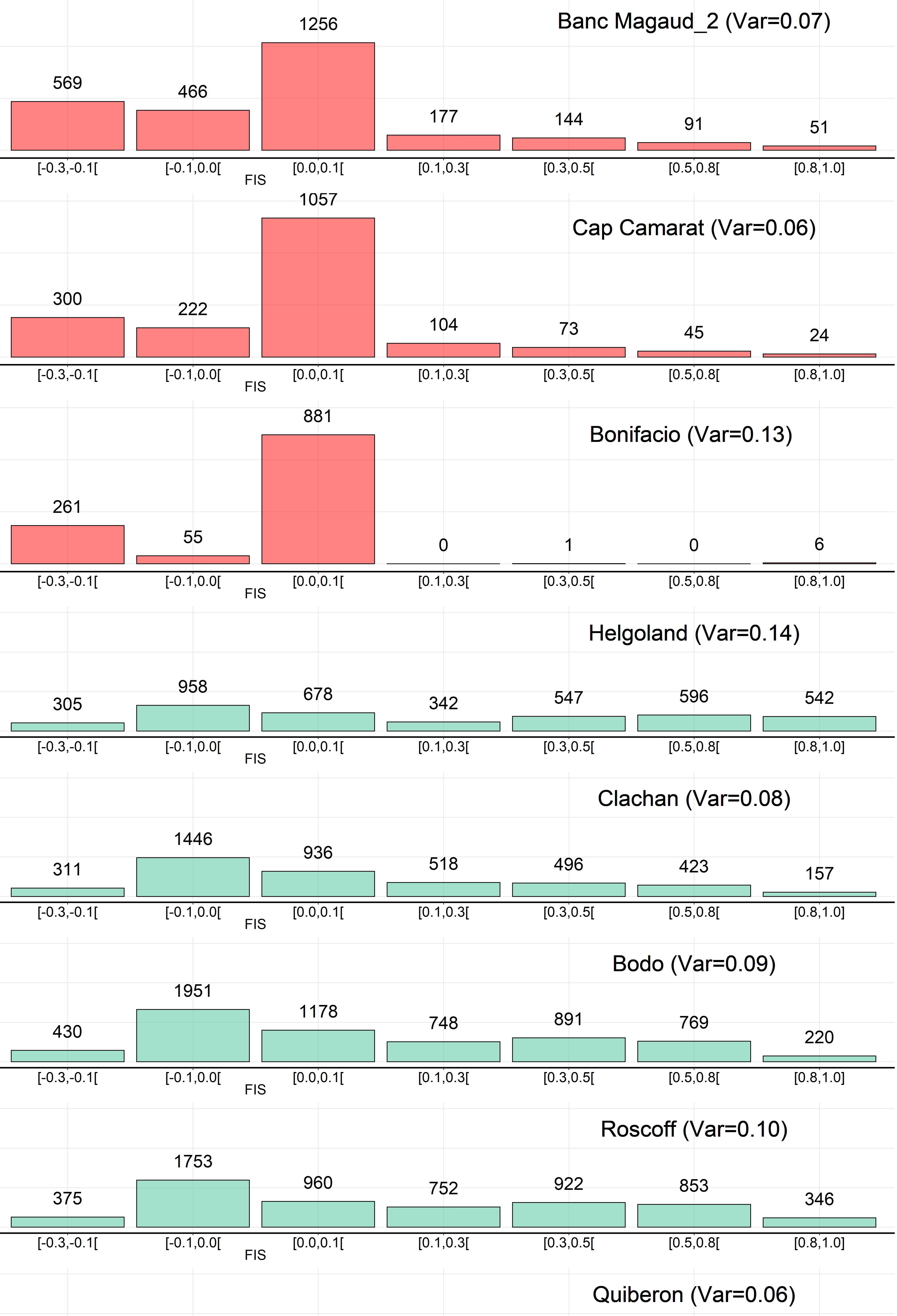

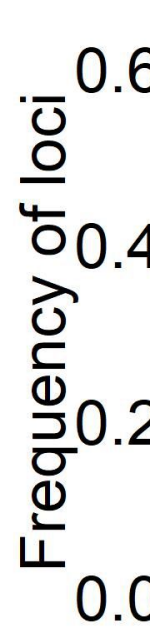

B

$[-0.1,0.0[\quad$ FIS

$[0.1,0.3[$

$+$

\section{Bonifacio $(\operatorname{Var}=0.13)$}
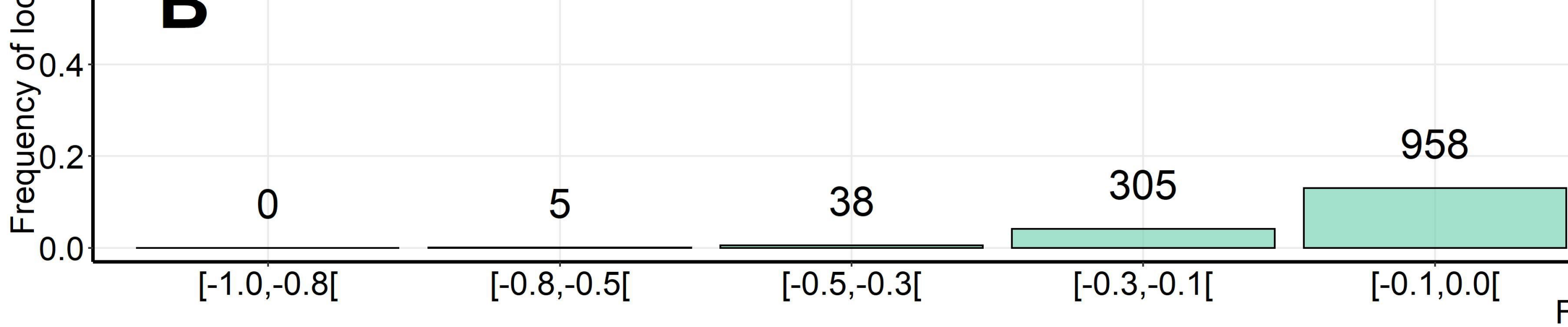

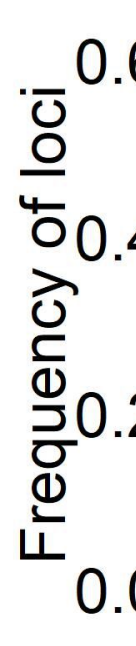
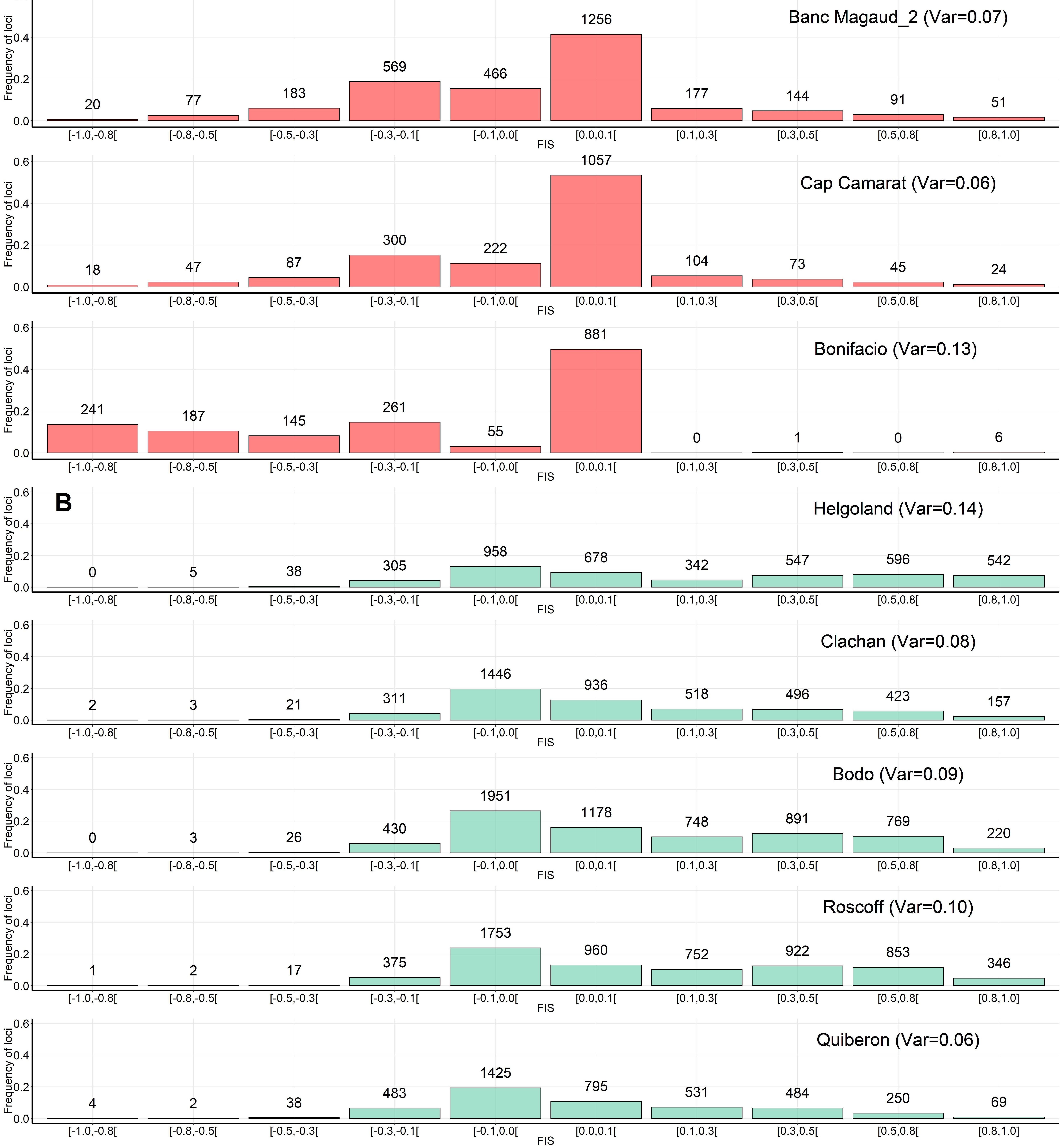

1425

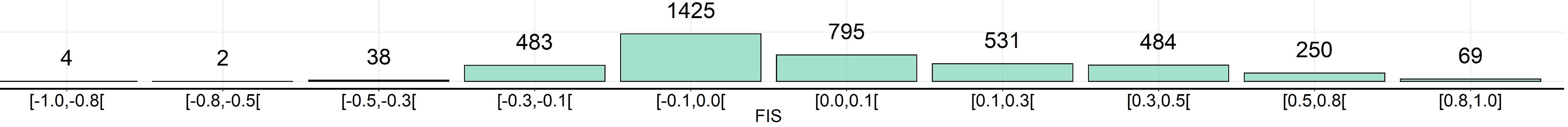




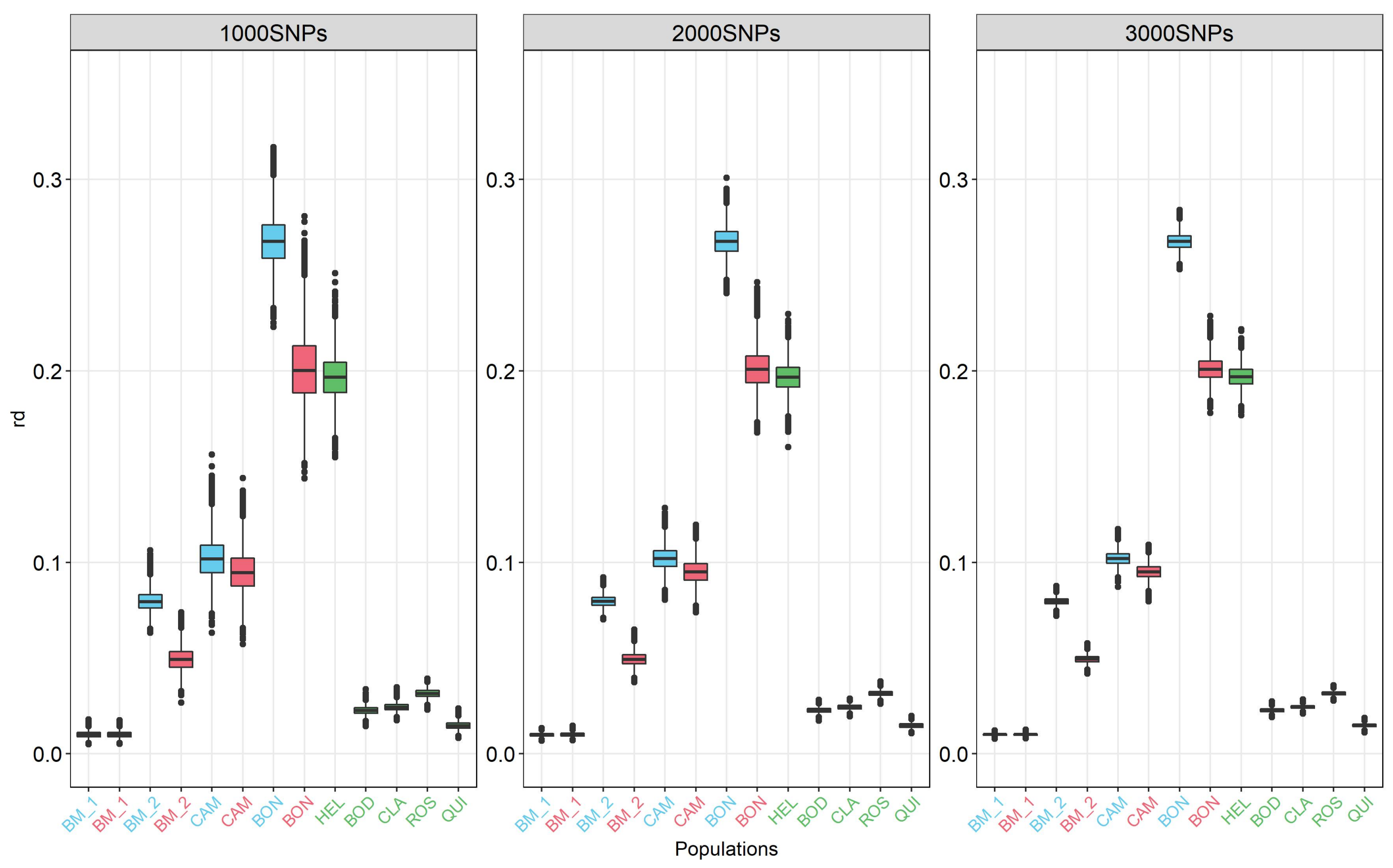

追 L. rodriguezii 追 L. rodriguezii (cc) 户 L. digitata 


\section{Supplemental Information for:}

\section{Genomic signatures of clonality in the deep water kelp Laminaria rodriguezii}

Lauric Reynes, Thierry Thibaut, Stéphane Mauger, Aurélie Blanfuné, Florian Holon, Corinne Cruaud, Arnaud Couloux, Myriam Valero, Didier Aurelle

\section{Table of Contents:}

\section{Supplementary materials}

Table S1. Genetic variation within populations of Laminaria digitata. $\mathrm{N}$, number of individuals successfully genotyped, Ho, observed heterozygosity, He, expected heterozygosity, $\mathrm{F}_{\mathrm{IS}}$, average fixation index, $\overline{\boldsymbol{r}_{\boldsymbol{d}}}$, average multilocus linkage disequilibrium. FIs and $\overline{\boldsymbol{r}_{\boldsymbol{d}}}$ values highlighted in bold indicate significant heterozygote deficit within populations ( $P$-val < $0.001)$ and significant linkage disequilibrium ( $P$-val $<0.001)$, respectively.

Table S2. Genotypic richness (R) and Pareto $(\beta)$ indexes estimated for populations of Laminaria rodriguezii. No $\beta$ value is reported at Banc Magaud_1 due to the absence of clonal lineages.

Figure S1. Spatial analyses at Banc Magaud_2. (A) the pairwise genetic distances were those previously used to assess clonal identity and (B) the spatial distance matrix (m) 


\begin{tabular}{|c|c|}
\hline $\begin{array}{l}\text { was generated from the positions of individuals within the } \\
\text { transect. Mantel tests between spatial and genetic } \\
\text { distances were significant ( } R=0.40, P<0.001) \text { after } 10000 \\
\text { permutations. LRBM2P12, LRBM } 2 \mathrm{P} 13 \text {, and LRBM2P14 } \\
\text { belong to the same clone, while LRBM } 2 \mathrm{P} 2 \text { is one of the } \\
\text { outliers highlighted in the study. (C) The linear regression } \\
\text { between genetic and spatial distances by including (red) or } \\
\text { excluding (blue) pairwise comparisons with the outlier. }\end{array}$ & \\
\hline $\begin{array}{l}\text { Figure S2. Genomic patterns of the three outliers as } \\
\text { comparison to other individuals of Laminaria rodriguezii. } \\
\text { (A) Percentage of private alleles per individual and (B) } \\
\text { percentage of heterozygosity per individual. }\end{array}$ & Page S6 \\
\hline $\begin{array}{l}\text { Figure S3. Average percentage of polymorphic loci (\%P) } \\
\text { within populations of }(\mathrm{A}) \text { Laminaria rodriguezii and (B) } \\
\text { Laminaria digitata obtained using a random sampling } \\
\text { approach implemented in a custom bash script (available at } \\
\text { https://github.com/rebecca-cj/revegetation). The } \\
\text { percentage of polymorphic loci was calculated for each } \\
\text { sample size from } 100 \text { random resamples. Standard error } \\
\text { from the mean from replicates is represented as error bars. }\end{array}$ & Page S7 \\
\hline Materials S1 & Pages S8-9 \\
\hline
\end{tabular}


Table S1

\begin{tabular}{lcccccccc}
\hline Population & Label & Lat. & Long. & $\mathbf{N}$ & $\mathbf{H}_{\mathbf{o}}$ & $\mathbf{H}_{\mathbf{e}}$ & $\mathbf{F}_{\text {IS }}$ & $\overline{\boldsymbol{r}_{\boldsymbol{d}}}$ \\
\hline Bodo & BOD & 67.2765 & 14.5747 & 23 & 0.14 & 0.18 & $\mathbf{0 . 2 3}$ & $\mathbf{0 . 0 2}$ \\
Clachan & CLA & 56.3171 & -5.5832 & 25 & 0.09 & 0.12 & $\mathbf{0 . 2 2}$ & $\mathbf{0 . 0 2}$ \\
Helgoland & HEL & 54.1779 & 7.8926 & 20 & 0.09 & 0.15 & $\mathbf{0 . 4 3}$ & $\mathbf{0 . 2 0}$ \\
Quiberon & QUI & 48.7275 & 4.0079 & 23 & 0.11 & 0.13 & $\mathbf{0 . 1 2}$ & $\mathbf{0 . 0 1}$ \\
Roscoff & ROS & 47.4700 & -3.0914 & 25 & 0.13 & 0.19 & $\mathbf{0 . 2 8}$ & $\mathbf{0 . 0 3}$ \\
\hline
\end{tabular}




\section{Table S2}

\begin{tabular}{lcc}
\hline Population & $\boldsymbol{\beta}$ & $\mathbf{R}$ \\
\hline Banc Magaud_1 & NA & 1.00 \\
Banc Magaud_2 & 2.00 & 0.80 \\
Cap Camarat & 3.32 & 0.90 \\
Bonifacio & 0.56 & 0.20 \\
\hline
\end{tabular}




\section{Figure S1}

(A)

\begin{tabular}{|c|c|c|c|c|c|c|c|c|c|c|}
\hline 0.212 & & & & & & & \multirow{2}{*}{\multicolumn{3}{|c|}{$\begin{array}{l}\text { Mantel test with } 10000 \\
\text { permutations }\end{array}$}} & $\begin{array}{l}\text { LRBM2P1 } \\
\text { LRBM2P2 }\end{array}$ \\
\hline 0.15 & 0.239 & & & & & & & & & LRBM2P3 \\
\hline 0.153 & 0.233 & 0.129 & & & & & & & & LRBM2P12 \\
\hline 0.154 & 0.233 & 0.129 & 0.001 & & & & & & & LRBM2P13 \\
\hline 0.153 & 0.233 & 0.129 & 0.002 & 0.002 & & & & & & LRBM2P14 \\
\hline 0.13 & 0.207 & 0.104 & 0.111 & 0.112 & 0.112 & & & & & LRBM2P15 \\
\hline 0.147 & 0.226 & 0.132 & 0.135 & 0.136 & 0.135 & 0.104 & & & & LRBM2P24 \\
\hline 0.152 & 0.234 & 0.137 & 0.12 & 0.119 & 0.12 & 0.112 & 0.132 & & & LRBM2P25 \\
\hline 0.15 & 0.225 & 0.136 & 0.135 & 0.135 & 0.134 & 0.106 & 0.128 & 0.128 & & LRBM2P26 \\
\hline 0.158 & 0.232 & 0.136 & 0.137 & 0.136 & 0.137 & 0.116 & 0.141 & 0.139 & 0.131 & LRBM2P27 \\
\hline
\end{tabular}

(B)
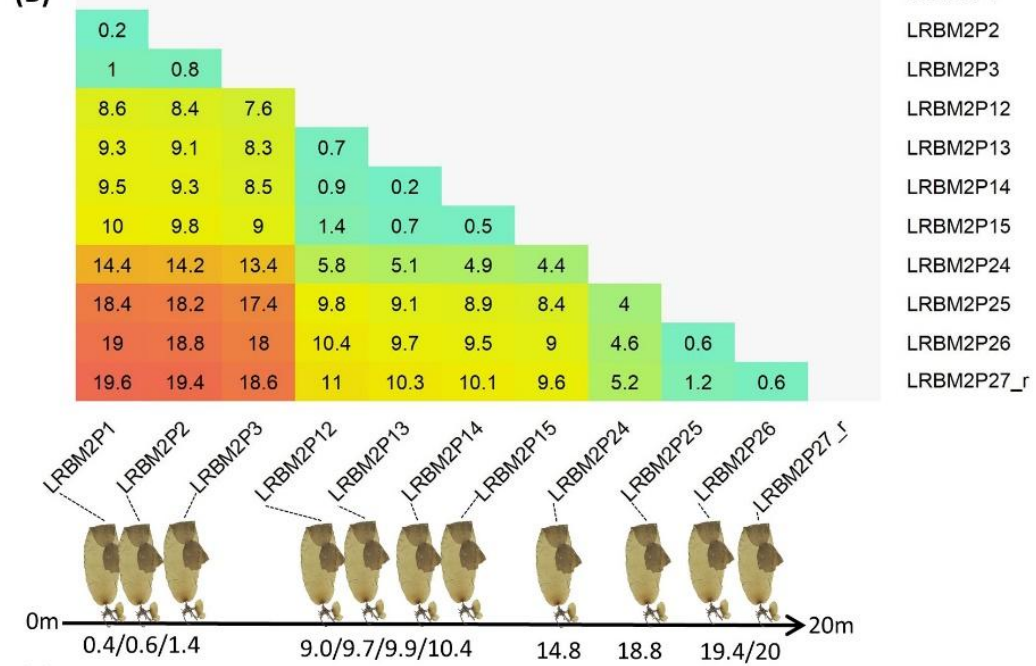

(C)

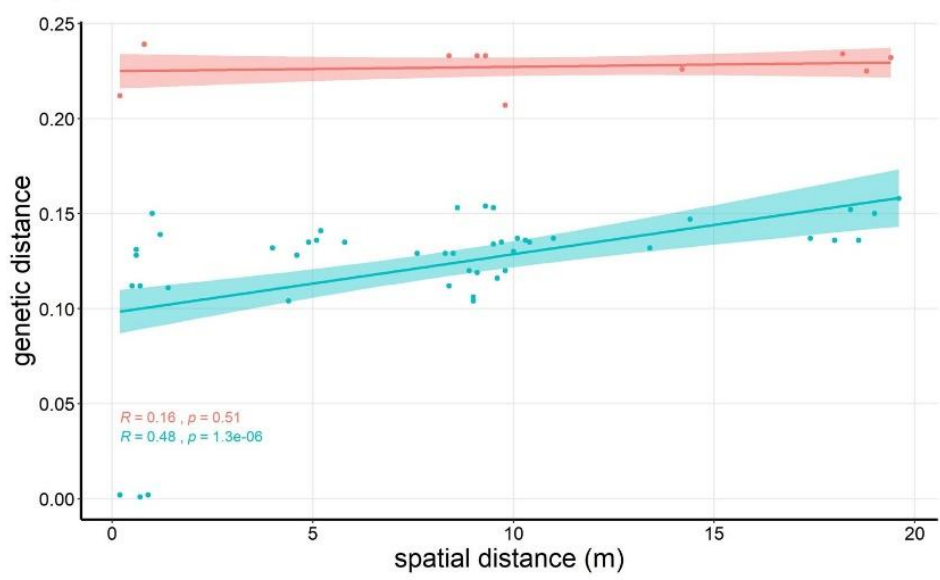

\section{Figure S2}




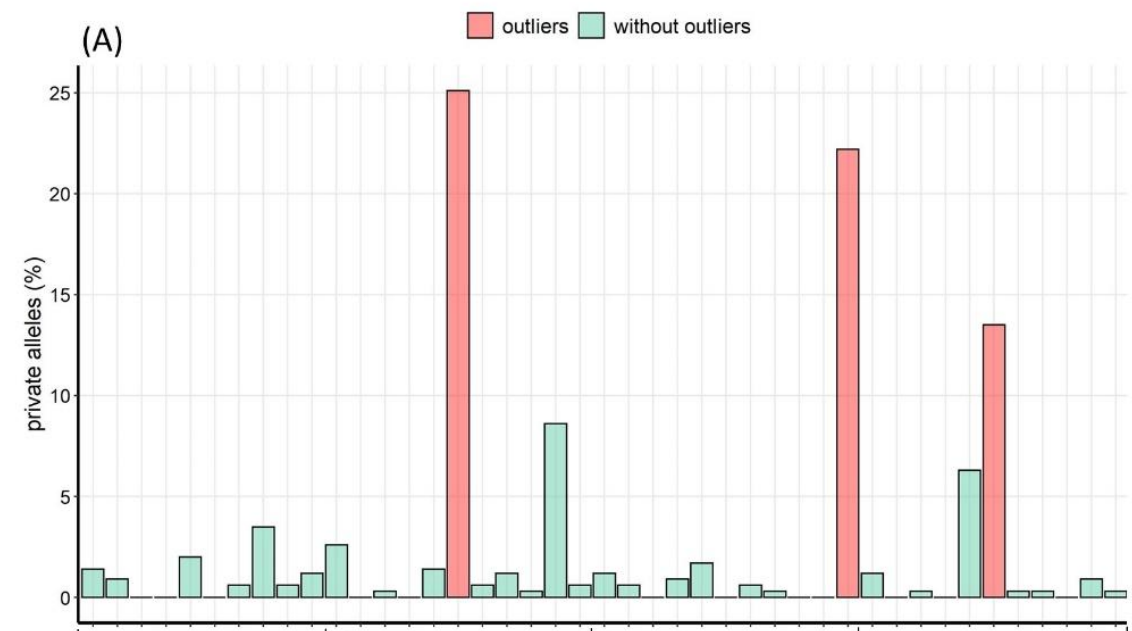

Banc Magaud_1 1 Banc Magaud_2 1 Bonifacio
(B)

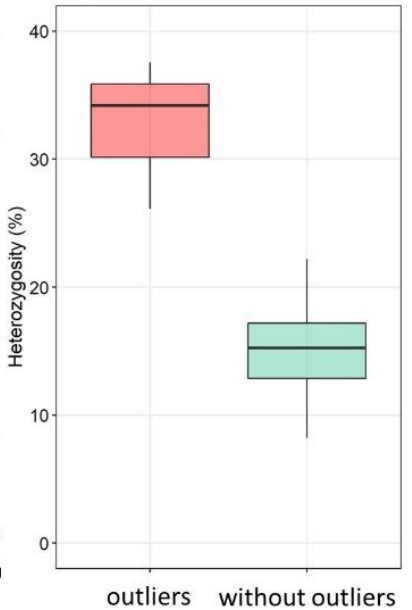




\section{Figure S3}
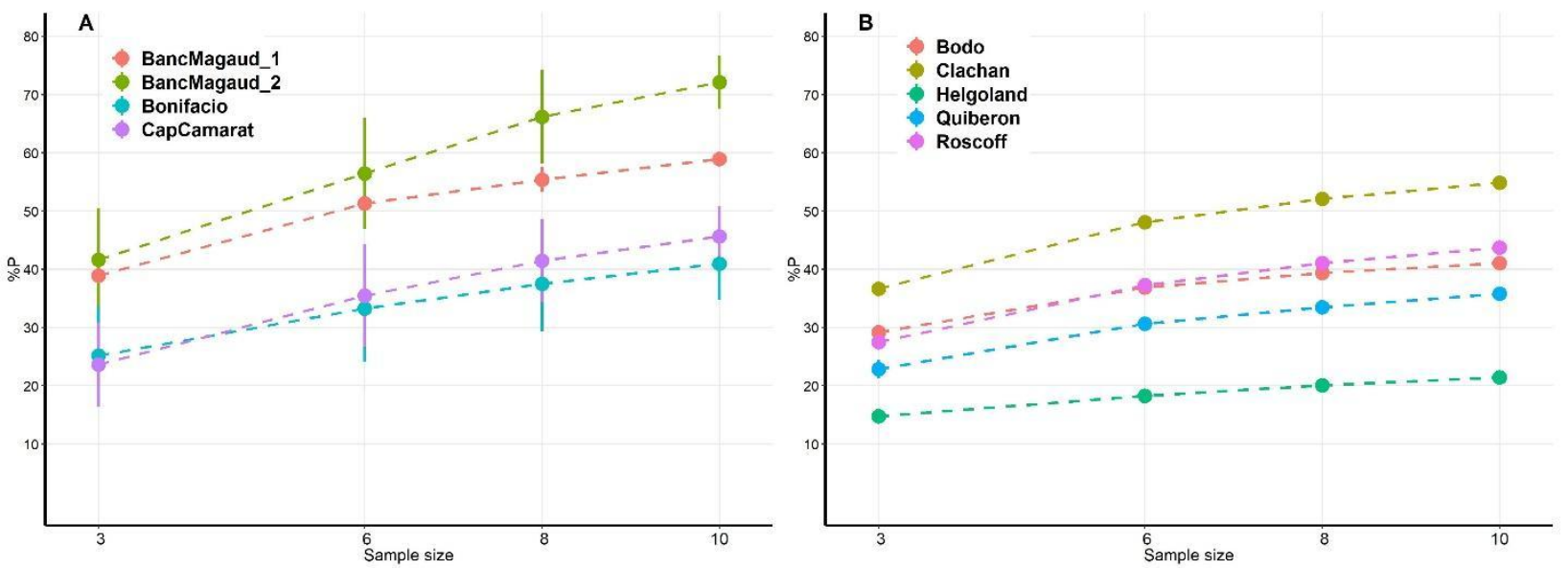


\section{Materials S1}

To address the effect of SNP filtering we started from the output of the catalog of 867513 loci of L. rodriguezii, in which 283864 SNPs were initially reported using the Stacks v2.4 bioinformatics pipeline (Rochette et al., 2019). Then, we selected a subset of informative SNPs by requiring a locus to be present at a frequency of greater than $80 \%$ at each of the four study sites. Additionally, we excluded SNPs with more than $80 \%$ heterozygosity and selected the first SNP of each RAD locus. As reported in the present study, we eliminated four individuals (with from $35 \%$ to $63 \%$ of missing genotypes) for which RAD-sequencing has been unsuccessful. At the end of this step, 21357 informative SNPs were genotyped among the 43 individuals of the present study, thus constituting the reference dataset for the following analyses. We applied many filtering cutoffs (see Table 4) to the reference dataset, using VCFtools v0.1.17 (Danecek et al., 2011), thus producing 15 VCF files. Using the same software, we computed the number of SNP passing the filter (SNPs count), the mean missing data rate per individual (missingness), and the mean read depth per individual (coverage) for each dataset. Finally, we computed both $F_{\text {IS }}$ and FST values (Weir \& Cockerham, 1984) using the HierFstat R package (Goudet, 2005) and the mean SNP error rate between replicates with the R function developed by Mastretta-Yanes et al., (2015). We also considered a dataset including SNPs for which genotypes are strictly identical between replicates (matching genotypes) to consider the effect of potentially problematic SNPs on population genetic summary statistics. The results of these analyses are presented in the main manuscript (see Table 4).

\section{REFERENCES}


Danecek, P., Auton, A., Abecasis, G., Albers, C. A., Banks, E., DePristo, M. A., ... Durbin, R. (2011). The variant call format and VCFtools. Bioinformatics, 27(15), 2156-2158. doi: 10.1093/bioinformatics/btr330

Goudet, J. (2005). Hierfstat, a package for $r$ to compute and test hierarchical F-statistics. Molecular Ecology Notes, 5(1), 184-186. doi: 10.1111/j.1471-8286.2004.00828.x

Mastretta-Yanes, A., Arrigo, N., Alvarez, N., Jorgensen, T. H., Piñero, D., \& Emerson, B. C. (2015). Restriction site-associated DNA sequencing, genotyping error estimation and de novo assembly optimization for population genetic inference. Molecular Ecology Resources, 15(1), 28-41. doi: 10.1111/1755-0998.12291

Rochette, N. C., Rivera-Colón, A. G., \& Catchen, J. M. (2019). Stacks 2: Analytical methods for paired-end sequencing improve RADseq-based population genomics. Molecular Ecology, 28(21), 4737-4754. doi: 10.1111/mec.15253

Weir, B. S., \& Cockerham, C. C. (1984). Estimating F-Statistics for the analysis of population structure. Evolution, 38(6), 1358-1370. doi: 10.1111/j.1558-5646.1984.tb05657.x 